This item was submitted to Loughborough's Research Repository by the author.

Items in Figshare are protected by copyright, with all rights reserved, unless otherwise indicated.

\title{
Microneedle assisted micro-particle delivery from gene guns: experiments using skin-mimicking agarose gel
}

PLEASE CITE THE PUBLISHED VERSION

http://dx.doi.org/10.1002/jps.23835

PUBLISHER

(c) Wiley Periodicals, Inc. and the American Pharmacists Association

\section{VERSION}

AM (Accepted Manuscript)

LICENCE

CC BY-NC-ND 4.0

\section{REPOSITORY RECORD}

Zhang, Dongwei, Diganta Bhusan Das, and Chris D. Rielly. 2014. "Microneedle Assisted Micro-particle Delivery from Gene Guns: Experiments Using Skin-mimicking Agarose Gel”. figshare.

https://hdl.handle.net/2134/14356. 


\title{
Microneedle assisted micro-particle delivery from gene guns: Experiments using skin mimicking agarose gel
}

\author{
Dongwei Zhang, Diganta B Das*, Chris D Rielly \\ Department of Chemical Engineering, Loughborough University, Loughborough LE113TU, UK \\ ( ${ }^{\star}$ Corresponding Author; Email: D.B.Das@lboro.ac.uk)
}

A set of laboratory experiments has been carried out to determine if microneedles (MNs) can enhance penetration depths of high speed micro-particles delivered by a type of gene gun. The micro-particles were fired into a model target material, agarose gel, which was prepared to mimic the viscoelastic properties of porcine skin. The agarose gel was chosen as a model target as it can be prepared as a homogeneous and transparent medium with controllable and reproducible properties allowing accurate determination of penetration depths. Insertions of various MNs into gels have been analysed to show that the length of the holes increases with an increase in the agarose concentration. The penetration depths of micro-particle were analysed in relation to a number of variables, namely, the operating pressure, the particle size, the size of a mesh used for particle separation and the MN dimensions. The results suggest that the penetration depths increase with an increase of the mesh pore size, due to the passage of large agglomerates. As these particles seem to damage the target surface, then smaller mesh sizes are recommended; here a mesh with a pore size of $178 \mu \mathrm{m}$ was used for the majority of the experiments. The operating pressure provides a positive effect on the penetration depth, i.e., it increases as pressure is increased. Further, as expected, an application of MNs maximizes the micro-particle penetration depth. The maximum penetration depth is found to increase as the lengths of the MNs increase, e.g., it is found to be $1272 \pm 42 \mu \mathrm{m}, 1009 \pm 49 \mu \mathrm{m}$ and $656 \pm 85 \mu \mathrm{m}$ at 4.5 bar pressure for spherical micro-particles of $18 \pm 7 \mu \mathrm{m}$ diameter when we used MNs of $1500 \mu \mathrm{m}, 1200 \mu \mathrm{m}$ and $750 \mu \mathrm{m}$ length, respectively.

Key words: Gene gun, stainless steel micro-particles, microneedle, penetration depth, agarose gel 


\section{Introduction}

Gene guns have been shown to be useful for delivery of DNA vaccines into tissues ${ }^{1-5}$. These delivery systems are primarily accelerators of micro-particles, which deliver DNA loaded micro-particles into target tissues to achieve the desired gene transfection ${ }^{2,6-8}$. The micro-particles are generally required to penetrate to certain depths within the target to carry out the desired effect of gene delivery and, as such, the penetration depth of the micro-particles is one of the major variables studied in gene delivery research. Ziegler ${ }^{9}$ has indicated that an acceptable DNA delivery requires that the micro-particles penetrate into the target skin tissue by approximately $20-100 \mu \mathrm{m}$. However, the top layer of the skin, i.e., the stratum corneum (SC), limits the penetration depths for the particles ${ }^{10,11}$ due to its resistance to particle motion. Furthermore, whatever the particles achieve in terms of penetration depths in the target tissue, depends on a number of key variables such as the operating pressure, particle size, properties of the target tissue, etc. ${ }^{12-16}$.

In general, the micro-particles follow two routes of penetration into the target tissue, which are the extracellular and intercellular routes ${ }^{16}$. The extracellular route is followed during delivery of large particles, when the tissue is damaged between the cell boundaries. Soliman ${ }^{17}$ has suggested that particles which have larger diameters, e.g. 15 - $100 \mu \mathrm{m}$, are expected to penetrate by extracellular failures of the tissues. In this case, an increased size of lower density micro-particles can achieve sufficient momentum to breach the target layer and penetrate further to the desired depths inside the target tissue $\mathrm{e}^{18,19}$. Due to their biocompatibility and low cost, biomedical grade stainless steel and polymeric micro-particles are considered to be good choices to replace high density gold particles. For example, polymeric micro-particles of 15.5 and $26.1 \mu \mathrm{m}$ diameters have been delivered at $6 \mathrm{MPa}$ in a conical nozzle by Quinlan et al. ${ }^{20}$. Kendall ${ }^{21}$ has also used converging-diverging nozzle to deliver polystyrene micro-particles of 26.1 and $39 \mu \mathrm{m}$ average diameters at $4 \mathrm{MPa}$ to velocities of 365 and $350 \mathrm{~m} / \mathrm{s}$, respectively. Truong et al. ${ }^{22}$ have used polystyrene particles of 15 and $48 \mu \mathrm{m}$ diameter at 6 MPa in a contoured shock tube (CST). Liu et al. ${ }^{23}$ have operated with polystyrene particles of diameter $40 \mu \mathrm{m}$ at $6 \mathrm{MPa}$ to study the particle velocity for a CST. Mitchell et al. ${ }^{16}$ have used stainless steel micro-particles of $25 \mu \mathrm{m}$ diameter and concluded that the particles can penetrate up to $150 \mu \mathrm{m}$ into excised canine buccal mucosa at a velocity of $170 \mathrm{~m} / \mathrm{s}$. Polystyrene particles of 15.5, 25, 48 and 99 $\mu \mathrm{m}$ diameters have also been operated at 2, 4 and $6 \mathrm{MPa}$ pressures in the light gas gun (LGG) by Mitchell et al. ${ }^{16}$. 
Based on these previous studies, it can be concluded that the diameters of low density micro-particles (e,g., polystyrene and stainless steel) which have been used in gene delivery typically ranged between 15 to $100 \mu \mathrm{m}$. Furthermore the operating pressures for particle delivery fall in the range between 2 to 6 $\mathrm{MPa}$, which may be considered to be high in many devices. Xia et al. ${ }^{24}$ have indicated that $200 \mathrm{psi}$ (1.4 $\mathrm{MPa}$ ) should be the maximum pressure for biolistic transfer of micro-particles to tissue without any damage to the target material. Traditionally, heavy metal micro-particles including tungsten ${ }^{25-28}$ and gold $^{2,29,30}$ coated with DNA have been used for targeting tissues. These elements have high densities and are well suited for particle bombardment. However, tungsten particles have several disadvantages such as non-biocompatibility, DNA degradation and toxicity to cells ${ }^{31-33}$. Gold particles carry the disadvantage of being very expensive. Cell damage is another problem for the biolistic micro-particle delivery. Sato et al. ${ }^{34}$ have used various types of gene guns to transfer genes into live rodent brain tissue, which confirmed mechanical damage on cells from micro-particles delivery. However, cell damage decreases from a decrease in particle size and operating pressure ${ }^{2,24,35}$.

Addressing the points above, a method of delivering micro-particles is explored in this work using a model experimental rig, which mimics a typical gene gun for delivery of micro-particles. A model experimental rig is preferred over a gene gun as it allows control and monitoring of important operating variables. A polytetrafluoroethylene (PTFE) made ground slide is used in the current rig, which prevents impact of the pressurized gas onto the target skin and slows down the velocity of microparticles while achieving the purpose of minimized cell damage. The rig also makes use of the application of the microneedle (MN) to overcome the effect of the barrier of micro-particle target, allowing a number of micro-particles to reach the deeper area of the target tissue via the holes created by MNs. Micro-particles of biocompatible stainless steel, which have a lower density compared to gold and tungsten and are cheaper than gold, are used in this work.

The mechanisms of MN insertion in the skin and, in particular, its application in creating well-defined holes in the skin have been studied for some years. For example, McAllister et al. ${ }^{36}$ have observed that holes are created in skin indicating that there is an amount of residual strain that remains after the MNs have been removed. They have used a cylindrical MN of $20 \mu \mathrm{m}$ diameter to perform staining experiments which indicated that the holes remain after removal of the MNs. Davis et al. ${ }^{37}$ have used a conical hollow MN of $720 \mu \mathrm{m}$ length and $30-80 \mu \mathrm{m}$ tip radius to insert into the skin to study the holes created after removal the MN. In addition, Martanto et al. ${ }^{38}$ have used a MN array with a needle length 
of $1000 \mu \mathrm{m}$ and width of $200 \mu \mathrm{m}$ by $50 \mu \mathrm{m}$ to create visible holes on a rat skin for drug delivery. Kalluri

et al. ${ }^{39}$ have applied conical MNs of $559 \pm 14 \mu \mathrm{m}$ length, $213 \mu \mathrm{m}$ base width and $4 \mu \mathrm{m}$ tip radius on the skin and reported that they create micro-channels of $60 \mu \mathrm{m}$ surface diameter and $160 \pm 20 \mu \mathrm{m}$ depth.

The above studies on gene guns show some situations where the gene guns could be coupled with MNs for improved delivery of micro-particle delivery from gene guns in the practice. In a recent review paper, Zhang et $\mathrm{al}^{40}$ have discussed the potential uses of these coupled systems in detail and therefore they are not discussed in length. This paper is focused on developing a MN based system for micro-particle penetration. For the purpose of this paper, agarose gel is chosen as a target, as it is a homogeneous and semi-clear material, providing the convenience to measure the micro-particle penetration depth by a digital optical microscope. Furthermore changing the agarose concentration allows alteration of the viscoelastic properties of the target from one experiment to another, which is difficult to achieve in the case of real tissue, e.g. porcine skin. In our experiments, agarose gel with viscoelastic properties which mimicked porcine skin is used to study micro-particle penetration. In addition, this paper is aimed at studying the penetration depth in relation to important variables which affect the particle penetration, e.g., operating pressure, particle size and $\mathrm{MN}$ length, using the skin mimicked concentration of agarose and others.

\section{Material and Methodology}

\subsection{Materials}

Irregular shaped and spherical micro-particles made of biocompatible stainless steel were purchased from Goodfellow Cambridge Ltd. (Huntingdon, UK) and LPW Technology Ltd. (Daresbury, UK), respectively. Detailed characterization of the micro-particles is introduced in section 2.3.2. Agarose powder was purchased from Sigma-Aldrich Company Ltd. (Gillingham, UK). Porcine ear skin samples were obtained from a local butcher.

Stainless steel meshes, used for micro-particle separation were bought from MeshUK, Streme Limited (Marlow, UK).Two different MN arrays (AdminPatch MN 1200 and 1500) which are 1200 and $1500 \mu \mathrm{m}$ long were purchased from nanoBioSciences limited liability company (LLC) (Sunnyvale, CA, USA). In addition, an in-house stainless steel MN array which is made of $750 \mu \mathrm{m}$ long was used in this study. The characterization of each MN array is explained in section 2.3.3. 


\subsection{Experimental design}

A detailed description of a MN based micro-particle delivery system has been introduced in a previous study by Zhang et al. $^{41}$. Generally, the system comprises of an acceleration, a separation and a deceleration stage. In such a system a pellet of micro-particles is accelerated by a pressurized gas to a sufficient velocity in the acceleration stage. It is then separated into a number of small particles by impaction onto a mesh in the separation stage. Finally, the separated particles penetrate the target which is the final deceleration stage. In order to achieve the aims of this paper and carry out an indepth study of the penetration depth of the solid micro-particle, an improved version of the

experimental rig $^{41}$ is used in this work. Figure 1 a shows the sections corresponding to the acceleration, separation and deceleration stages. The improvement has been made in the deceleration stage which contains the target material for the particles to penetrate. For the purpose of this paper, a sliced test tube (described below) has been placed in the deceleration stage to hold in place the agarose gel, which acts as a target for the micro-particles. Both ends of the glass tube are open, which make it convenient to remove the agarose gel without damage, following a penetration test.

In this work, a setup modified from Zhang et al. ${ }^{41}$ is used. It is made by using a sliced test tube (see Figure 1b) which allows observation of particle penetration without the need to slice the gel. It is based on a polytetrafluoroethylene (PTFE) mold which is placed inside the sliced test tube, as shown in detail in Figure 1b. A test tube is sliced into approximately $1 \mathrm{~cm}$ thick sections where both sides are kept open. The mold is then inserted into a tube piece. The void space in the mold contains the agarose gel. The mold can separate into two parts, providing a convenient method for the removal of the gel. Based on the application of the mold, the agarose gel is prepared into uniform pieces of of $1 \mathrm{~cm}$ thickness with smooth surfaces on both sides to provide a good environment for a digital microscope to detect the micro-particle penetration.

\subsection{Experimental methods}

\subsubsection{Data acquisition}

\subsubsection{Preparation of skin mimicking agarose gel}

In this work, agarose gel is used as a skin mimicking target, which allows visualization of the particles and measurement of the particle penetration depths as a function of number of variables as discussed later. The method of skin mimicking in this work is based on preparing an agarose gel, which has 
similar viscoelastic properties to porcine skin samples collected from a local butcher. The skin samples used were the intact fresh skin collected from the ears of young piglets (5-6 months old).

The procedure to determine the skin mimicking agarose gel to be used as a target for micro-particles is as follows. First of all, a rotational viscometer with parallel plate geometry (AR $1000-N$, TA Instruments) was used to characterise the dynamic viscoelastic properties of the porcine skin samples. In order to increase the accuracy of the skin property measurement and avoid wall slippage, an upper plate of $2 \mathrm{~cm}$ diameter and containing teeth (1 $\mathrm{mm}$ deep) was chosen, whereas abrasive silicon carbide paper was fixed to the base plate. This ensures that internal viscoelastic properties of skin samples are measured, rather than characteristics of their wall slip. The porcine skin samples were cut into a number of small pieces which have the same size as the parallel plates for rheological analysis. Oscillation test was chosen to analyse the skin and agarose gel samples in this work. In order to mimic the porcine skin properties using agarose gel, a wide range of angular frequencies has been used in the viscometer, to investigate the important time scales of the viscoelastic media. However, in the current paper, results from only a narrow range of frequency are presented. All of the tests are performed in the linear regime, at constant strain and temperature of $1 \%$ and $20^{\circ} \mathrm{C}$, respectively. The angular frequency was varied from 84 to $474 \mathrm{rad} / \mathrm{sec}$ to measure the dynamic viscoelastic properties.

After determining the dynamic viscoelastic properties of the porcine skin, agarose gels with different concentrations of agarose were analysed to identify the gel that best matches the dynamic viscoelastic property of the porcine skin. The gels were moulded into $2 \mathrm{~cm}$ diameter slices and a similar thickness as the porcine skin to provide comparability between results of the two materials.

The experimental data for both skin and agarose gels are used to determine the storage modulus ( $G^{\prime}$ ) (see equation 1) and loss modulus $\left(G^{\prime \prime}\right)^{42}$ (equation 2). Those two moduli are related to the strain amplitude $\left(\gamma_{0}\right)$, stress amplitude $\left(\sigma_{0}\right)$ and a phase lag between the strain and stress $(\delta)$ of the material. G' of the samples shows the stored energy in the material and indicates the elastic properties. On the other hand, the G" indicates the energy dissipated as heat and characterises the viscous properties. The data are used to calculate dynamic viscosity $\left(\mu{ }^{\prime}\right)$ of the samples as functions of angular frequency $(\omega)^{42}$. 


$$
\begin{aligned}
\mathrm{G}^{\prime} & =\frac{\sigma_{0}}{\gamma_{0}} \cos \delta \\
\mathrm{G}^{\prime \prime} & =\frac{\sigma_{0}}{\gamma_{0}} \sin \delta
\end{aligned}
$$

Where

$$
\begin{aligned}
& \sigma_{0}=\sigma / \cos (\omega t) \\
& \gamma_{0}=\gamma / \cos (\omega t-\delta) \\
& \mu^{\prime}=G^{\prime \prime} / \omega
\end{aligned}
$$

In the above equations, $\mathrm{t}, \sigma$ and $\gamma$ represent the time, stress and strain, respectively.

\subsubsection{Determination of the micro-particle penetration depths and hole lengths}

A previous study ${ }^{41}$ has shown that the particle penetration depths can be measured by a digital optical microscope (Eclipse 3100 \& Digital Sight, Nikon). As described in §2.2, a mold is used to prepare the agarose gels to uniform size of $2 \mathrm{~mm}$ width, $8 \mathrm{~mm}$ length and $1 \mathrm{~cm}$ thickness (see Figure 1b) and avoided the need for later slicing. The gel was conveniently removable which avoids damage prior to further analysis. In the experiment, a uniform force to pierce the MN array into the gel was achieved by manually pressing it on a flat plate which is placed on the back of the MN array. The MN patch was pressed carefully until it reached the flat surface of the gel. The gel was taken out from the mold and analysed by microscope directly. Several digital images were taken, and the particle penetration depth was measured by an image processing software (Image J) using the digital images. Calibration of these images was conducted using a graticule. The time scale between $\mathrm{MN}$ removal and observation of holes was approximately 30 seconds. The experiment of $\mathrm{MN}$ insertion was repeated three times for the gel per concentration to increase the reliability of the results and verify the length of the pierced holes. For the measurement of the micro-particle penetration depth, the procedure was the same with the detection of the hole lengths. The only difference is that the micro-particles were fired into the gel. The time scale between firing micro-particles and observation of penetration depth was approximately 2 minutes.

\subsubsection{Characterization of the micro-particles}

Two supplies of biocompatible stainless steel made of both irregular and spherical micro-particles were chosen for the purpose of this paper. Figure $2 a$ shows a scanning electron microscopic (SEM) image of the applied irregular stainless steel micro-particles; most of the particles have rough surfaces and the average sphericity was determined as $0.66 \pm 0.13$ from image analysis. Based on the analysis 
of a particle size analyser (Coulter LS130, BECKMAN COULTER, Inc., USA), the particle size distribution was determined which is found to be in the range of 10 to $80 \mu \mathrm{m}$, while the the Sauter mean diameter of the particles is $30 \pm 15 \mu \mathrm{m}$. The bulk density and porosity of these micro-particles are $3.35 \pm 0.05 \mathrm{~g} / \mathrm{cm}^{3}$ and $58.0 \pm 0.6 \%$, respectively. A second supply of micro-particles (Figure $2 \mathrm{~b}$ ) was much more spherical with an average sphericity of $0.92 \pm 0.05$. Their size distribution range was between 1 and $20 \mu \mathrm{m}$ and their Sauter mean diameter was $18 \pm 7 \mu \mathrm{m}$.

\subsubsection{Characterization of the MN}

In this work, three different MNs were used to determine the effects of geometry on the particle penetration process. Three different lengths of the MNs were chosen so as to confirm that the trend of results obtained from one particular MN length is observed for another length of MN. First of all, a commercially available MN patch, namely, AdminPatch MN 1500, has been applied. This maintains continuity of our work as it is the same MN array that was used in our previous study ${ }^{41}$. The array has a total of $31 \mathrm{MNs}$ which are distributed as a diamond shape on a $1 \mathrm{~cm}^{2}$ circular area. The spaces on the side line and diagonal lines are 1546, 1643 and $3000 \mu \mathrm{m}$ (see Figure 3); the length, thickness and width of each of the MNs are 1500, 78 and $480 \mu \mathrm{m}$, respectively. In addition, AdminPatch MN 1200 was used (see Figure 3a) which has 43 flat MNs and the MNs are distributed more closely on the same size patch as MN 1500. The spaces on the diagonal lines are 1252, 1970 and $2426 \mu \mathrm{m}$. The thickness and width of each MN are the same as AdminPatch MN 1500 array except the length is $1200 \mu \mathrm{m}$. Finally, an in-house fabricated MN array was also used in this work with a view to increase the range of variables which should provide a better understanding of the micro-particle delivery

process. Figure $3 \mathrm{~b}$ shows the in-house fabricated MN array which consist of 3 cylindrical MNs on a circular patch. As can be seen, the tip of the needle, made of biocompatible stainless steel, is polished flat smooth using sand paper. The pitch, i.e., the centre-to-centre distance between two MNs is 500 $\mu \mathrm{m}$, and the length and diameter of each $\mathrm{MN}$ are 750 and $250 \mu \mathrm{m}$, respectively. The main characteristics of the above three MN arrays are listed in Table 1.

\section{Results and Discussions}

\subsection{Preparation of skin mimicking agarose gel}

Two porcine skin samples cut from ears were used to study the dynamic viscoelastic properties, as described in section 2.3.1.1. The results are presented in section 3.1.1, whereas the dynamic viscoelastic properties of skin mimicking agarose gel are presented in section 3.1.2 in detail. Porcine Page 8 of $\mathbf{2 5}$ 
skin has been used previously as a substitute to human skin, as it has similar histological and physiological properties ${ }^{43-45}$ and is often used in transdermal drug delivery studies ${ }^{46}$. Similarly, agarose gel has been used to mimick skin tissues in previous studies. For example, Koelmans et al. ${ }^{47}$ have used agarose gel as a skin simulant to mimic the dermis layer of the skin to study how MNs interact with soft tissue. Arora et al. $^{48}$ have chosen agarose gel as a model tissue material to study the penetration of pulsed micro-jets. Some discussions on the rheology of these materials, which mostly relate to dynamic stress-strain relationship, can be found in the literature ${ }^{49-52}$. We choose to determine the rheological properties in-house as it provides us the option to control the conditions under which they are measured.

\subsubsection{Dynamic viscoelastic properties of porcine skin}

In this set of experiments, the dynamic viscoelastic properties of porcine skin were tested at a constant strain value of $1 \%$ and wide range of angular frequency from 84 to $474 \mathrm{rad} / \mathrm{s}$ by a rotational viscometer with parallel plate geometry. Storage modulus (G') of the samples shows the stored energy and explains their elastic properties, whereas the loss modulus (G") indicate the energy dissipated as heat and characterises the viscous properties. The temperature on the parallel plate during the experiment was controlled at $20^{\circ} \mathrm{C}$ to reduce the thermal effects on the results. Figures $4 \mathrm{a}-\mathrm{c}$ show the dynamic viscoelastic properties of two porcine skin samples as a function of angular frequency. As can be seen, both samples show that the G' and G' increase due to an increase in angular frequency. Moreover, G' and G" are found to match well for the two skin samples, showing consistency of the measurements. Although G" shows a slight difference before $300 \mathrm{rad} / \mathrm{s}$, the difference seems to be negligible for most practical purposes. Figure 4c shows that the dynamic viscosity ( $\left.\eta^{\prime}\right)$ decreases with an increase of the angular frequency. The dynamic viscosities of the two skin samples match closely for angular frequencies above $240 \mathrm{rad} / \mathrm{s}$. The above results, which suggest that reproducible skin properties can be obtained, provide some confidence to characterise the skin using this viscometer. Finally, it points out that the dynamic viscosity of the porcine skin samples over a wide range of strain rates remains approximately constant at about $20 \mathrm{~Pa}$ s.

\subsubsection{Porcine skin mimicking agarose gel}

In order to simulate the properties of skin by agarose gel, a gel that has the same size as the porcine skin sample was prepared using a mold and analysed by the viscometer at the same maximum strain and range of oscillation condition as was used for porcine skin. After testing a wide range 
concentration of agarose gel we find that the viscoelastic properties of the agarose gel where agarose concentration ranges from 0.026 to $0.027 \mathrm{~g} / \mathrm{ml}$ is close to porcine ear skin. As presented in Figures $4 \mathrm{a}-$ c, the concentration of agarose gel is varied from 0.025 to $0.03 \mathrm{~g} / \mathrm{m}$. The results of gel which have agarose concentration lower than $0.025 \mathrm{~g} / \mathrm{ml}$ are not presented as their viscoelastic behaviour are significantly different from those of the porcine skin. Figure $4 a$ shows the storage modulus of the agarose gel increases with increasing angular frequency, in agreement with the results for the skin sample. In addition, the storage modulus of the $0.0265 \mathrm{~g} / \mathrm{ml}$ agarose gel shows an excellent match with the porcine skin. For the loss modulus, the agarose gel shows a slight decreasing tendency with an increase of angular frequency. The results of porcine skin samples present a different performance with agarose gel. However, the gel concentrations which range from $0.0265 \mathrm{~g} / \mathrm{ml}$ to $0.0280 \mathrm{~g} / \mathrm{ml}$ represent good matches in terms of the loss modulus variations of porcine skin. Figure 4c shows the agarose gel has a dynamic viscosity that decreases with increasing angular frequency (shear-thinning) which shows a same performance with porcine skin. After the comparison, agarose gel of $0.0265 \mathrm{~g} / \mathrm{ml}$ is considered to match with the porcine skin. The other concentration of agarose gel shows a significant difference with porcine skin at lower angular frequcey. Overall, the results of $0.0265 \mathrm{~g} / \mathrm{ml}$ concentration of agarose gel seem to fit better with the porcine skin samples, if compared with the results of other concentration of agarose. As expected, these results demonstrate that it is possible to mimic the porcine skin using an agarose gel, based on the matching of the dynamic viscoelastic properties of the skin. It is not possible to obtain an exact match over a whole range of deformation conditions, but nevertheless, the $0.0265 \mathrm{~g} / \mathrm{ml}$ concentration of agarose gel provides a reasonable match and hence will be used to study micro-particle penetration for the remainder of the paper.

\subsection{Microneedle insertion}

There has been a significant amount of $\mathrm{MN}$ insertion research which has focused on studying skin behaviour after a MN array has been applied. The skin reforms after the removal of the MN due to its inherent viscoelasticity ${ }^{36,53}$. Therefore, the length of the MNs is often longer than the desired depth in the $\operatorname{skin}^{38,54-56}$. Furthermore, the holes created by the MN close up slowly after the MNs have been removed from the skin. In this case, the agarose gel is prepared into $1 \mathrm{~cm}$ thick section (see section 2.2). A skin mimicked agarose gel $(0.0265 \mathrm{~g} / \mathrm{ml})$ is chosen to study the effect of the $M N$ insertion on the lengths of hole created by them. In addition, different concentration of agarose were used to investigate the $\mathrm{MN}$ array effect on the hole lengths depending on different properties of the target material. The hole length is of significant importance in this study as it relates to the particle 
penetration depth, as discussed later. In the experiment, agarose gel is molded to give a flat surface which is used as an object of reference for the insertion of MN. Observations of MN insertion and removal into agarose gel, results in holes which are smaller than the dimensions of the MNs; these holes close rather quickly to an equilibrium size after the $\mathrm{MN}$ has been removed, indicating that the target material has relatively short relaxation times for its elastic response.

Figure 5 shows the length of the created holes by different MNs for various concentrations of agarose in the gels. As expected, the length of the hole is less than the MN length. This is because the MNs do not penetrate into the gel fully. In addition, the results show that the hole length a positive correlation with the concentration of agarose in the gel. This is because an increased concentration of gel causes an increase in both the loss and storage moduli and the dynamic viscosity, which help to retain the hole size for longer duration. Figure 5 also shows that the average hole lengths increased with increasing needle length. The holes created by AdminPatch MN 1500 and 1200 close up fully at 0.02 $\mathrm{g} / \mathrm{ml}$ concentration of agarose. The thickness of the MNs $(78 \mu \mathrm{m})$ on those AdminPatch designs are so small that the holes are unable to remain open when viscoelastic moduli and viscosities fall too low. However, the holes created by in-house fabricated needle remained intact at $0.02 \mathrm{~g} / \mathrm{ml}$ concentration of agarose as the diameter of these needles is considerably larger at $250 \mu \mathrm{m}$.

In the experiment, 10 holes were measured to obtain the average lengths of the pierced hole.These experimental results suggest that the average hole lengths are $1149 \pm 58,1048 \pm 69$ and $656 \pm 44 \mu \mathrm{m}$ for skin mimicked agarose gel $(0.0265 \mathrm{~g} / \mathrm{ml})$ for AdminPatch MN 1500 (length $=1500 \mu \mathrm{m}$ ), AdminPatch MN 1200 (length $=1200 \mu \mathrm{m}$ ) and in-house fabricated needle (length $=750 \mu \mathrm{m}$ ), respectively. The results indicate that the holes shrink to about $87 \%$ of the original lengths of the $\mathrm{MN}$ after approximately 5 minutes. In addition, the diameter of the holes created by the in-house fabricated needle shrink to about $156 \pm 12 \mu \mathrm{m}$. For AdminPatch MN 1500 and 1200, the widths of the hole are $302 \pm 26$ and $292.8 \pm 18 \mu \mathrm{m}$, respectively. The holes shrunk to about $62 \%$ of the width of the MN. McAllister et al. ${ }^{36}$ reported a residual hole radius of $6 \mu \mathrm{m}$ following insertion of MNs with radius of 10 $\mu \mathrm{m}$ such that the holes shrunk to about $60 \%$ of the radius of the MNs. It shows that the results of hole shrinkage between skin mimicked concentration of agarose and real skin are well correlated. The above results provide some confidence that the skin mimicked concentration of agarose is acceptable to replace the skin for further studies of the micro-particle penetration. 


\subsection{Measurements of the micro-particle penetration depth}

A previous study ${ }^{41}$ has indicated that pellets which are bound together with $40 \mathrm{mg} / \mathrm{ml}$ PVP concentration provides a good pellet separation, if a mesh of $178 \mu \mathrm{m}$ pore size is used. In continuation of the previous paper, pellets of $40 \mathrm{mg} / \mathrm{ml}$ PVP concentration are applied in this work to find out the effect of the key variables on the micro-particle penetration depth. In this case, an agarose gel was prepared into $1 \mathrm{~cm}$ thick slice (see section 2.2) and used for the analyse of the penetration depth in relation to the mesh pore size, operating pressure, particle size, $\mathrm{MN}$ length and agarose gel concentration (this represents different viscoelastic properties). Each condition is studied three times to accurately determine the penetration depth of micro-particles and verify the accuracy of the results. It is worth mentioning that the maximum operating pressure is limited to 5 bar as the PTFE made ground slide might crash after the impaction at the end of the wall. The crashed ground slide may destroy the mesh and affect the experiment results.

\subsubsection{Effect of the mesh pore size}

In theory, the particle penetration depths should increase with an increase of the mesh pore size, which allows larger particles to pass through ${ }^{41}$; consequently, they have more momentum to breach the target. In order to determine the significance of this effect for the particle delivery, two different meshes with pore size of 178 and $310 \mu \mathrm{m}$ were applied and their effects on the micro-particle penetration were studied in this section. Figure $6 a$ shows the side view of the micro-particles penetration in the skin mimicked agarose gel, without any MN application for a mesh of $178 \mu \mathrm{m}$ pore size. As can be seen, the pellet has broken up into the micro-particles as it has passed through the mesh and the micro-particles are mainly distributed around the centre of the gel, i.e., the central impact point of the pellet on the mesh.

A large number of particles are visible close to the top surface, but the vast majority have penetrated only about $100 \mu \mathrm{m}$ into the gel. There are such a large number of particles in this region close to the surface that individual penetrations are difficult to distinguish.

However, the top surface of the gel can be defined as shown in Figure 6a. Some micro-particles penetrate deep into the gel, which are clearly visible. There are about 30 micro-particles which have penetrated deeper into the gel and their positions are analysed by image processing software (ImageJ) to measure the average maximum penetration depth which is found to be $210 \pm 23 \mu \mathrm{m}$ at 5 bar 
operating pressure. It is worth mentioning that the penetration depths of micro-particles are obtained after zooming figure to measure the distance between micro-particle and top surface based on the scale. These are shown in the figure. In the magnified view of Figure $6 \mathrm{a}$, it is clear that some particles penetrate deep into the gel, by creating a channel or hole, which remains open even after the particles have come to rest. The magnified view also shows that some of the particles with the largest penetration depths are agglomerates; increased agglomerate sizes would lead to higher particle momentum and hence greater penetration depths.

Figure $6 \mathrm{~b}$ shows the micro-particle penetration without MN application following separation of the pellet by a mesh of $310 \mu \mathrm{m}$ pore size at 5 bar driving pressure. As can be seen, a lot of micro-particles are distributed around the surface of the gel. Furthermore, larger penetration depths were often found due to the application of this mesh, because the large agglomerated particles have more momentum and hence are better at piercing the target. The maximum penetration depth in this case is more than for the results (Figure 6a) obtained from the mesh of $178 \mu \mathrm{m}$ pore size. However, large agglomerated particles which pass the mesh may damage the target area, as is indicated by the uneven/broken surface of the gel. Therefore, these results suggest that the $310 \mu \mathrm{m}$ mesh pore size may not be acceptable for the MN based system for the conditions chosen in these experiments. Zhang et al. ${ }^{41}$ also point out that the application of mesh with $178 \mu \mathrm{m}$ pore size has a higher passage percentage and a more effective pellet separation. Considering the passage percentage and pellet separation state, led to the conclusion that the $178 \mu \mathrm{m}$ pore size of mesh should be used for the rest of the study for determining the effect of operating pressure, particle size, MN size and agarose gel concentration on the penetration depth.

\subsubsection{Effect of the operating pressure and particle size}

The operating pressure and the particle size are two major variables which affect the micro-particle penetration depths. The momentum of the particles is directly related to those two variables. Here the AdminPatch MN 1500 has been applied to investigate the MN effect on the particle penetration depth and the combined effect of the operating pressure, particle size and $\mathrm{MN}$ array on the penetration depth is presented in Figure 7. In this case, spherical stainless steel micro-particle of $18 \mu \mathrm{m}$ and irregular stainless steel micro-particle of $30 \mu \mathrm{m}$ are used to study the particle size effect on the penetration depth. As expected, the application of a $M N$ array has a very significant effect on the penetration depth. This is because the holes created by the $\mathrm{MN}$ array provide a selective path for the 
micro-particle penetration into the agarose gel. The holes created by the MN may close up after the particles enter the gel and, as such, they get fully embedded in the gel.

For the results without needle application, the penetration depths present a positive correlation with the operating pressure. The penetration depth increases gradually with an increase of the operating pressure due to the increased velocity and momentum of the particles entering the target material. In addition, the particle momentum increases due to increased particle size which also provides a positive effect on the penetration depth. The latter result agrees qualitatively with the effect of changing the mesh pore size on the penetration depth. In that case the larger particles sizes arose from agglomerates remain un-separated after passage through the mesh; these particles penetrated further.

For the result with $\mathrm{MN}$ applications, the operating pressure has a positive effect on the penetration depth for $30 \mu \mathrm{m}$ diameter particle. However, it seems that the operating pressure and particle size are not necessarily the major variables that influence the particle penetration depths when MNs are applied. The length of the pierced holes is the primary factor which maximizes the particle penetration depth. As can be seen, the $18 \mu \mathrm{m}$ diameter particles provide the maximum penetration depth for 3 to 5 bar operating pressures. The length of the pierced hole is $1149 \pm 58 \mu \mathrm{m}$ when AdminPacth MN 1500 is inserted (section 3.2). It helps the particles to enter into a deeper area at lower pressure. However, there is little difference between the penetration depths for those two particle sizes. This is because in practice it is not just the particle size, but an interplay of variables which determines the penetration depth. In this case, it seems that uniformity of the pore size forms fairly similar sized particle agglomerates. Therefore, the penetration depth is not directly influenced by the size of the individual particles.

Figure 8 shows the micro-particle penetration in the skin mimicked agarose gel after the application of AdminPatch MN 1500. As can be seen, there are a number of micro-particles in the gel which have entered through the pierced holes. Figure 8 a shows the spherical micro-particles penetration in the agarose gel. As is evident, a large number of micro-particles have entered from the left size of the pierced hole. This is because the MN hole at the left side of the image is located around the central impact point of the pellet on the mesh. The number of micro-particles in the hole decreases as its position moves away from the central impact point. Figure 8b presents the irregular micro-particles 
penetration at the same operating condition as for Figure 8a. It shows that the amount of the irregular micro-particles penetrated in the pierced holes is less than that of the spherical micro-particle. This is can be explained as follows. The thickness of the $\mathrm{MN}$ is only $78 \mu \mathrm{m}$ and the thickness of the pierced hole is further reduced due to the shrinkage of the gel. Furthermore, the average diameter of the irregular particles is about $30 \mu \mathrm{m}$ and hence it may form larger agglomerates, which are comparable in size with the thickness of the holes. These factors may result in significant non-penetration of the irregular particles into the holes. On the other hand, the average diameter of the spherical particles is $18 \mu \mathrm{m}$ which is significantly smaller than the thickness of the hole. Therefore, more spherical particles penetrate into the holes.

\subsubsection{Effect of the MN length on particle penetration depth}

In general, the maximum penetration depth is related to the size of the applied MN due to the effect of the holes created. However, as presented in Figure 9, the maximum micro-particle penetration depths differ significantly between each MN array at various operation pressures of 3 to 5 bar. In this case, spherical stainless steel micro-particle of $18 \mu \mathrm{m}$ average diameter is used due to its uniform particle size distribution. Further, it seems that they can be easily identified inside the gel. As can be seen, the penetration depths increase with increasing $M N$ length. An increased length of the MN makes longer holes which provide a positive effect on micro-particle delivery. Figure 9 also shows that the penetration depth gradual increases from an increase of operation pressure, which agrees with the result presented in the previous section. As expected, the three $\mathrm{MN}$ arrays used in this work provide a positive effect on the micro-particle penetration depth allowing operation a significantly lower driving pressure. From these results, the maximum penetration depth can reach $1273.2 \pm 42.3,1009 \pm 49$ and $659 \pm 85 \mu \mathrm{m}$ at 4.5 bar pressure for AdminPatch MN 1500 and 1200 and in-house fabricated needle, respectively. The results indicate that the maximum penetration depth could be controlled by the size of the $\mathrm{MN}$ and it is related to the desired depth of the target. MN assisted micro-particle delivery provides a controllable penetration depths of micro-particles inside the target using various MN sizes. In practice, it should allow micro-particles to penetrate into epidermis or further to dermis when the pierced holes cross the epidermis layer of skin. In addition, the maximum penetration depth increases gradually with the increase in operating pressure. It can be safely stated that the effects of the holes on the micro-particle delivery (e.g., the penetration depth) can be fine-tuned by the operating pressure. 


\subsubsection{Effect of the agarose gel concentration on the particle penetration depth}

Generally, the resistance to the particle penetration into a target should be different if the rheological properties of the target change. However, it is not clear at this moment how significant the changes in the property of the target would be on determining the penetration depths. To address this issue, agarose gels of different concentrations were chosen to imitate the condition of different targets. In this case, spherical (regular) stainless steel micro-particles are used and the penetration of the microparticles in gels of different agarose concentrations is studied in order to find out the effect of the target property on the micro-particle penetration depths.

Figure 10 shows the effect of the agarose gel concentrations on the particle penetration depth. As can be seen, the penetration depth decreases from an increase of the agarose gel concentration without MN. This is because the higher gel concentration has a greater viscosity which provides more resistance to the micro-particle delivery. However, this does not happen when a $\mathrm{MN}$ is used. As discussed in section 3.2, the lengths of the $\mathrm{MN}$ holes increase from an increase of the gel concentration, because the increased viscosity and elasticity are better able to hold the holes open. Therefore, the application of the MNs causes the penetration depths to increases as the agarose gel concentration increases. Figure 10 also shows that the experimental error is lower for higher concentration gel. This is related to the lengths of the holes which remain intact for higher agarose concentrations. In addition, the figure shows that the length of the $\mathrm{MN}$ correlates well to the penetration depth, similar to the results in section 3.3.3.

\subsubsection{Further discussions}

Overall, three physical cell targeting approaches including passive diffusion delivery, solid MN assisted micro-particle delivery and needle free biolistic micro-particle delivery can now be applied as shown in Figure 11. The route of the passive diffusion delivery (Figure 11a) is that the drugs permeate through the aperture of the SC and diffuse into the target ${ }^{57}$. It is a non-invasive method, and therefore does not damage the skin. However, it is limited by the diffusion length of the drug molecules and is considered as a low efficiency drug delivery method for targeting cells ${ }^{57}$. Needle-free biolistic micro-particle delivery (Figure 11c) is a great improvement for the transdermal gene delivery. The principle of this technique is that DNA is loaded on micro-particles which are accelerated to a sufficient velocity to pierce into the epidermis layer of the skin to achieve the DNA transfection. In the last case, DNA loaded micro-particle delivery is based on using a micro-needle to overcome the skin surface which 
enhance the penetration depth of micro-particles in the skin as compared to needle-free biolistic microparticle delivery ${ }^{41}$. As presented in Figure $11 \mathrm{~b}$ the micro-particles penetrate through the pierced hole to reach the desired layer of skin. A controllable maximum penetration depth of micro-particles can be achieved by varying the hole length (see Figure 11b). It is more convenient and flexible, compared with needle-free micro-particle delivery. In addition, the micro-particles are able to deliver into the dermis layer of skin to allow deeper tissue to be transfected, depending on the length of hole created by the MN.

The conditions considered in this paper for micro-particle penetration study have been shown to be useful to gain an insight to the dependence of the penetration of the micro-particles on many key variables in relation to the MN assisted micro-particle delivery from gene guns. The penetration depths of the micro-particles were analysed with respect to variations in mesh pore size, operating pressure, particle size, MN length and agarose gel concentration.

For the effect of the mesh on penetration, larger pore sizes allow large agglomerated particles to pass through, providing a higher particle passage percentage of the micro-particles ${ }^{41}$. High-speed of large agglomerated particles carry higher momentum and penetrate further into the target, but they are also more likely to cause damage to external tissues. Previously, a number of researchers have shown that cell and tissue damages are particular problems for the biolistic tranfection due to the impaction of micro-particles ${ }^{2,34,58-60}$. In the present case, a mesh with $310 \mu \mathrm{m}$ of pore size allows the passage of larger agglomerate which achieves a greater penetration depth in the skin mimicking agarose gel (see Figure 6a). It does not allow the micro-particle delivery due to the damage. However, O'Brien et al. ${ }^{2}$ have shown that cell damage occurs after the impaction of high-speed micro-particles but it decreases with a decreased particle size. The use of a mesh with pore size of $178 \mu \mathrm{m}$ yields well-separated particles which then can be discriminated as individual particles at a deeper level of the gel (see Figure $6 b)$. It provides better operation due to the blockage of the largest agglomerated particle, despite the negative effect on the passage percentage ${ }^{41}$.

Based on a consideration of particle momentum, the operating pressure and particle size are the key variables that affect the penetration depths. The impaction velocity of the particles is directly related to the operating pressures. An increased velocity implies that the micro-particles have more momentum to pierce into a deep level of the target. Therefore, the penetration depth increases with an increase in the operating pressure. In addition, an increased particle size provides a positive effect on the Page 17 of $\mathbf{2 5}$ 
penetration depth due to the increased momentum. In this case, the average penetration depth for the $30 \mu \mathrm{m}$ diameter stainless steel micro-particles is $168 \pm 24 \mu \mathrm{m}$ at 5 bar pressure. For the stainless steel micro-particles of $18 \mu \mathrm{m}$ diameter, it only has a penetration depth of $101 \pm 16 \mu \mathrm{m}$. Zhang et al. ${ }^{41}$ have shown that the micro-particles reach a velocity of $122 \mathrm{~m} / \mathrm{s}$ at 5 bar pressure using the MN based system. Earlier, Mitchell et al. ${ }^{16}$ have concluded that stainless steel micro-particles of $25 \mu \mathrm{m}$ diameter can penetrate $150 \mu \mathrm{m}$ into excised canine buccal mucosa at a velocity of $170 \mathrm{~m} / \mathrm{s}$. It matches well with the penetration of the stainless steel micro-particles in the skin mimicked concentration of agarose in this paper. The penetration route for needle free biolistic micro-particle delivery is presented in Figure $11 \mathrm{c}$ in detail.

As expected, an application of a MN array provides a positive effect on the micro-particle penetration depth. The maximum penetration depth of the micro-particles is presented with a significant increment from the results without MN application. However, the length of the pierced holes became the primary factor which enhances the particle penetration depths. An increased needle length provides a positive effect on the length of the pierced holes, which maximize the penetration depth. However, the maximum penetration depth of the spherical micro-particles reaches $1272 \pm 42,1009 \pm 49$ and $656 \pm$ $85 \mu \mathrm{m}$ at 4.5 bar pressure for AdminPatch MN 1500 and 1200 and the in-house fabricated needle, respectively. Those penetration depths were never achieved previously. In our case, the applied operating pressure is lower than other relevant gene gun system. For example, Quinlan et al. ${ }^{20}$ have used a conical nozzle employed at 60 bar to accelerate polymeric micro-particles. Mitchell et al. ${ }^{16}$ have fired stainless steel micro-particle into canine buccal mucosa at 20 bar pressure using light gas gun. A lower operating pressure causes a decreased velocity of micro-particle which may avoid severe tissue damage. In addition, an increased penetration depth of micro-particle allows deeper tissue to be transfected to achieve an efficient DNA transfection in the tissue if DNA is coated on the micro-particle. Further, one of the main advantages of the current approach is that the use of the ground slide (see Figure 1a) slows down the velocities of micro-particles and prevents the pressurized gas to reduce the impact force on tissue to minimize the cell damage. Also it is worth mentioning that the viscoelastic properties of the target have two important effects on the penetration of the micro-particles; an increased viscosity and elastic modulus provide (i) greater resistance to particle motion and (ii) affect the relaxation of the target material and hence determine the lengths of the pierced holes for a fixed geometry of MN. However, the desired depths can be achieved by changing the size of the MN and the operating pressure. 
As mentioned earlier the aim of this paper was to relate the penetration depth to various parameters. Indeed the extent of delivery, i.e., the mass of particles delivered with and without MNs, is a very important question that should be analysed in detail. This is related to a number of other issues (e.g., number of needles/holes per unit area (needle/hole density)). Furthermore, the effect of the operating pressure and/or particle size on the pore width at the target surface may be an important factor that controls the extent of delivery rate. These aspects were not studied in this paper but we plan to analyse these in the future.

\section{Conclusions}

In this paper, a solid MN based system has been presented for an application on the study of microparticle penetration. For the investigation of the particle penetration depth, agarose gel was chosen to mimic porcine skin due to its homogeneous and semi-clear properties which provides an ideal target material for measuring the micro-particle penetration depth as a function of other variables, e.g., pressure and particle size. For the purpose of this paper, it was found that the dynamic viscoelastic properties of a gel with $0.0265 \mathrm{~g} / \mathrm{ml}$ concentration of agarose were close to values for porcine skin; therefore this concentration of agarose gel was adopted for the bulk of the experiments in this work. Insertions of various lengths of $\mathrm{MN}$ in different concentrations of agarose gel have been examined to investigate the effect of the MN length of the pierced hole in the target. An increase in length of the MN or the gel concentration leads to an increased hole length. The penetration depth of the microparticles in the skin mimicked concentration of agarose was analysed in relation to the pore size of mesh, operating pressure, particle size and MN size. It was shown that the penetration depth increases with an increase of the above four variables. In particular, the MN length is shown to be a primary variable which maximizes the penetration depth of the micro-particles. Finally, different concentrations of agarose gel were chosen to imitate the conditions of various targets. Based on a MN application, the maximum penetration depth was shown to provide a positive correlation with gel concentration. It indicates that the property of the target should be considered carefully before using the MN based system. Based on the target property, a specific length of MN array should be decided for the micro-particle penetration to a desired depth. In conclusion, the MN based system is useful for micro-particle delivery where the damage of the target from the gas/particles is eliminated and the micro-particle system can be designed to reach the desired depth within the tissue. 


\section{Acknowledgement}

Loughborough University (UK) is acknowledged for providing a PhD studentship to Dongwei Zhang which made this work possible. Further, the technical supports from Mr Tony Eyre, Mr Mark Barron, Mr Jim Muddimer, Mr Terry Neale and Mr Steve Bowler are acknowledged.

\section{Reference}

1. S.K. Joseph, S. Sambanthamoorthy, G. Dakshinamoorthy, G. Munirathinam, K. Ramaswamy. Protective immune responses to biolistic DNA vaccination of Brugiamalayi abundant larval transcript-2, Vaccine, 30(45): 6477-6482 (2012).

2. J.A. O'Brien, S.C.R. Lummis. Nano-biolistics: a method of biolistic transfection of cells and tissues using a gene gun with novel nanometer-sized projectiles, BMC Biotechnology, 11: 66-71 (2011).

3. D.H. Fuller, P Loudon, C Schmaljohn. Preclinical and clinical progress of particle-mediated DNA vaccines for infectious diseases, Methods, 40(1): 86-97 (2006).

4. C. Trimble, C. Lin, C. Hung, S. Pai, J. Juang, L. He, M. Gillison, D. Pardoll, L. Wu, T. Wu. Comparison of the CD8+ $\mathrm{T}$ cell responses and antitumor effects generated by DNA vaccine administered through gene gun, biojector, and syringe, Vaccine, 21: 4036-4042 (2003).

5. B.J. Bellhouse, D.F. Sarphie, J.C. Greenford. Needleless syringe using supersonic gas flow for particle delivery, Patents No. (US5899880 A) (1999).

6. J.A. O'Brien, S.C.R. Lummis. Biolistic transfection of neuronal cultures using a hand-held gene gun, Nat. Protoc., 1(2): 977-981 (2006).

7. G. Zhang, M.E. Selzer. In vivo transfection of lamprey brain neurons by gene gun delivery of DNA, Exp. Neurol., 167(2): 304-311 (2001).

8. J.C. Sanford. Turning point article -The development of the biolistic process, In Vitro Cell. Dev. Biol., 36: 303-308 (2000).

9. A.S. Ziegler. Needle-free delivery of powdered protein vaccine: a new and rapidly developing technique, J. Pharm. Innov., 3: 204-213 (2008).

10. M.A.F. Kendall. Engineering of needle-free physical methods to target epidermal cells for DNA vaccination, Vaccine, 24: 4651-4656 (2006). 
11. E.E. Fuchs, S. Raghavan. Getting under the skin of epidermal morphogenesis, Nature reviews. Genetics, 3: 199-209 (2002).

12. S.M. Soliman, S. Abdallah, E. Gutmark, M.G. Turner. Numerical simulation of microparticles penetration and gas dynamics in an axi-symmertric supersonic nozzle for genetic vaccination, Powder Technology, 208: 676-783 (2011).

13. A. Arora, M.R. Prausnitz, S. Mitragotr. Micro-scale devices for transdermal drug delivery, Int. J. Pharm. 364: 227-236 (2008).

14. M. Zhang, W. Tao, P.A. Pianetta. Dynamics modelling of biolistic gene guns, Phys. Med. Biol., 52(5): 1485-1493 (2007).

15. M.B. Brown, G.P. Martin, S.A. Jones, F.K. Akomeah. Dermal and transdermal drug delivery systems: current and future prospects, Drug Delivery, 13(3): 175-187 (2006).

16. T.J. Mitchell, M.A.F. Kendall, B.J. Bellhouse. A ballistic study of micro-particle penetration to the oral mucosa, International Journal of Impact Engineering, 28: 581-599 (2003).

17. S.M. Soliman. Micro-particle and Gas Dynamics in an Axi-symmetric Supersonic Nozzle, University of Cincinnati (Cincinnati, USA), Thesis for the degree of Doctor of Philosophy in Aerospace Engineering. (2011).

18. M.P. Hardy, M.A.F. Kendall. Mucosal deformation from an impinging transonic gas jet and the ballistic impact of microparticles, Phys. Med. Biol., 50(19): 4567-4580 (2005).

19. D. Chen, C.A. Erickson, R.L. Endres, S.B. Periwal, Q. Chu, C. Shu, Y.F. Maa, L.G. Payne. Adjuvantation of epidermal powder immunization, Vaccine, 19(20-22): 2908-2917 (2001).

20. N.J. Quinlan, M.A.F. Kendall, B.J. Bellhouse, R.W. Ainsworth. Investigations of gas and particle dynamics in first generation needle-free drug delivery device, Shock Waves, 10: 395-404 (2001).

21. M.A.F. Kendall. The delivery of particulate vaccines and drugs to human skin with a practical, hand -held shock tube-based system, Shock Waves, 12: 23-30 (2002).

22. N.K. Truong, Y. Liu, M.A.F. Kendall. Gas and particle dynamics of a contoured shock tube for preclinical micro-particle drug delivery, Shock Waves, 15: 149-164 (2006). 
23. Y. Liu, M.A.F. Kendall. Numerical analysis of gas and micro-particle interactions in a hand-held shock tube device, Biomed Microdevices, 8: 341-351 (2006).

24. J.X. Xia, A. Martinez, H. Daniell, S.N. Ebert. Evaluation of biolistic gene transfer methods in vivo using non-invasive bioluminescent imaging techniques, BMC Biotechnology, 11: 62-72 (2011).

25. J.L. Morgan, D. Kerschensteiner. Shooting DNA, Dyes, or Indicators into Tissue Slices using the gene gun, Cold Spring Harb. Protoc., 12: 1512-1514 (2011).

26. R.S. Williams, S.A. Johnston, M. Riedy, M.J. DeVit, S.G. McElligott, J.C. Sanford. Introduction of foreign genes into tissues of living mice by DNA-coated microprojectiles, Proc. Natl. Acad. Sci. U.S.A., 88: 2726-2730 (1991).

27. A.V. Zelenin, A.V. Titomirov, V.A. Kolesnikov. Genetic transformation of mouse cultured cells with the help of high velocity mechanical DNA injection, FEBS Lett., 244(1): 65-67 (1989).

28. M.T. Klein, E.D. Wolf, R. Wu, J.C. Sanford. High-velocity microprojectiles for delivery of nucleic acids into living cells, Nature (London), 327: 70-73 (1987).

29. D. Rinberg. Pneumatic capillary gun for ballistic delivery of micro-particles, Applied Physics Letters, 87(1): 014103-014103-3 (2005).

30. W.E. Swain, F.D. Heydenburg, M.S. Wu, L.J. Barr, J.T. Fuller, J. Culp, J. Burkholder, R.M. Dixon, G. Widera, R. Vessey, M.J. Roy. Tolerability and immune responses in humans to a PowderJect DNA vaccine for hepatitis B., Dev. Biol (Basel). 104: 115-119 (2000).

31. S. Bastian, W. Busch, D. Kuhnel, A. Springer, R. Holke, S. Scholz, W. Pompe, M. Gelinsky, A. Potthoff, V. Richter, C. Ikonomidou, K. Schirmer, Toxicity of tungsten carbide and cobalt-doped tungsten carbide nanoparticles in mammalian cells in vitro, Environ. Health Perspect., 117(4): 530536 (2009).

32. Y. Yoshimisu, K. Tanaka, T. Tagawa, Y. Nakamura, T. Matsuo, S. Okamoto. Improvement of DNA/Metal Particle Adsorption in Tungsten-Based Biolistic Bombardment; Alkaline $\mathrm{pH}$ is Necessary for DNA Adsorption and Suppression of DNA Degradation, Journal of Plant Biology, 52: 524-532 (2009).

33. J.A. Russell, M.K. Roy, J.C. Sanford, Physical trauma and tungsten toxicity reduce the efficiency of biolistic transformation, Plant Physiol., 98: 1050-1056 (1992). 
34. H. Sato, S. Hattori, S. Kawamoto, I. Kudoh, A. Hayashi, I. Yamamoto, M. Yoshinari, M. Minami, H. Kanno. In vivo gene gun-mediated DNA delivery into rodent brain tissue, Biochem. Biophys. Res. Commun. 270(1): 163-170 (2000).

35. M. Uchida, X.W. Li, P. Mertens, H.O. Alpar. Transfection by particle bombardment: Delivery of plasmid DNA into mammalian cells using gene gun, Biochim. Biophys. Acta., 1790(8): 754-764 (2009).

36. D.V. McAllister, P.M. Wang, S.P. Davis, J.H. Park, P.J. Canatella, M.G. Allen, M.R. Prausnitz. Microfabricated needles for transdermal delivery of macromolecules and nanoparticles: fabrication methods and transport studies. PNAS, 100: 13755-13760 (2003).

37. S.P. Davis, B.J. Landis, Z.H. Adams, M.G. Allen, M.R. Prausnitz. Insertion of microneedles into skin: measurement and prediction of insertion force and needle fracture force, Journal of Biomechanics, 37: 1155-1163 (2004).

38. W. Martanto, S.P. Davis, N.R. Holiday, J. Wang, H.S. Gill, M.R. Prausnitz. Transdermal delivery of Insulin using MNs in vivo. Pharmaceutical Research, 21: 947-952 (2004).

39. H. Kalluri, A.K. Banga. Formation and closure of microchannels in skin following microporation, Pharm. Res., 28: 82-94 (2011).

40. D. Zhang, D.B. Das, C.D. Rielly. Potential of microneedle assisted micro-particle delivery by gene guns: A review, Drug Delivery, (accepted). (2013).

41. D. Zhang, D.B. Das, C.D. Rielly. An experimental study of microneedle assisted micro-particle delivery. Journal of Pharmaceutical Sciences, 102(10): 3632-3644, DOI: 10.1002/jps.23665 (2013).

42. M.A. Meyers, K.K. Chawla, (1999). Mechanical behaviour of materials, $1^{\text {st }}$ Edition, Prentice Hall, 98-103, ISBN: 9780132628174 ,

43. L. Dominik, G. Erwin, W.D. Paul, V.B. Hagen, M. Paul. Neuro-Muscular Differentiation of Adult Porcine Skin Derived Stem Cell-Like Cells, PLoSONE, 5(1): 8968-8976 (2010).

44. C. Edwards, R. Marks. Evaluation of biomechanical properties of human skin, ClinDermatol, 13: 375-380 (1995).

45. O.A. Shergold, N.A. Fleck, D. Radford. The uniaxial stress versus strain response of pig skin and silicone rubber at low and high strain rates. Int. J. Impact Eng., 32: 1384-1402 (2006). 
46. R. Kong, R. Bhargava. Characterization of porcine skin as model for human skin studies using infrared spectroscopic image. PubMed, 136(11): 2359-2366 (2011).

47. W.W. Koelmans, G. Krishnamoorthy, A. Heskamp, J. Wissink, S. Misra, N. Tas, (2013). Microneedle Characterization using a double-layer skin simulant, Mechanical Engineering Research, 3(2): 51-63

48. A. Arora, I. Hakim, J. Baxter, R. Rathnasingham, R. Srinivasan, D.A. Fletcher, S. Mitragotri, (2007). Needle-free delivery of macromolecules across the skin by nanoliter-volume pulsed microjets, Proceedings of the National Academy of Sciences of the U.S.A. (PNAS), 104(11): 4255-4260

49. H.Y.S. Huang, S. Huang, T. Gettys, P.M. Prim, O.L. Harrysson. A biomechanical study of directional mechanical properties of porcine skin tissue, Proceedings of the ASME 2013 International Mechanical Engineering Congress \& Exposition (IMECE2013), San Diego, California, USA, November 13-21, (2013).

50. Y.J. Zeng, K. Huang, C.Q. Xu, J. Zhang and G.C. Sun. Biorheological characteristics of skin after expansion. Biorheology, 38(5-6): 367-378 (2001).

51. F.H. Silver, J.F. Freeman, D. Devore. Viscoelastic properties of human skin and processed dermis. Skin Research and Technology, 7(1): 18-23 (2001).

52. F. Henry, F.C. Pierard, G. Cauwenbergh, G.E. Pierard. Age-related changes in facial skin contours and rheology. Journal of the American Geriatrics Society, 45(2): 220-222 (1997).

53. O. Olatunji, D.B. Das, M.J. Garland, L. Belaid, R.F. Donnelly. Influence of array interspacing on the force required for successful microneedle skin penetration: Theoretical and practical approaches. Journal of Pharmaceutical Sciences, 102(4): 1209-1221 (2013).

54. S.M. Bal, A.C. Kruithof, H. Lieb, M. Tomerius, J. Bouwstra, J. Lademann, M. Meinke. In vivo visualization of MN conduits in human skin using laser scanning microscopy. 7: 242-246 (2010).

55. R.F. Donnelly, R. Majithiya, T.R.R. Singh, D.I.J. Morrow, M.J. Garland, Y.K. Demir, K. Migalsks, E. Ryan, D. Gillen, C.J. Scott, D.A. Woolfsoon. Design, optimization and characterisation of polymeric MN arrays prepared by a novel laser-based micro moulding technique. Pharm. Res. 28: 41-57 (2010). 
56. C.S. Kolli, A.K. Banga. Characterization of solid maltose MNs and their use for transdermal delivery, Pharmaceutical Research, 25: 104-113 (2008).

57. G.M. Glenn, R.T. Kenney, L.R. Ellingsworth, S.A. Frech, S.A. Hammond, J.P. Zoeteweweij. Transcutaneous immunization and immunosticmulant strategies: capitalizing on the immunocompetence of the skin, Expert Rev., Vaccines, 2(2): 253-267 (2003).

58. M. Uchida, X.W. Li, P. Mertens, H.O. Alpar, (2009). Transfection by particle bombardment: Delivery of plasmid DNA into mammalian cells using gene gun, Biochim. Biophys. Acta., 1790(8):754-764

59. Y. Yoshida, E. Kobayashi, H. Endo, T. Hamamoto, T. Yamanaka, A. Fujimura, Y. Kagawa, (1997). Introduction of DNA into rat liver with a hand-held gene gun: Distribution of the expressed enzyme, [32P] DNA, and Ca2+ flux, Biochem. Biophys. Res. Commun. 234(3): 695 -700.

60. J.L. Thomas, J. Bardou, B. Mauchamp, L'hoste S., Mauchamp B., Chavancy G., (2001). A helium burst biolistic device adapted to penetrate fragile insect tissues, Journal of Insect Science, 1(9): 110 


\section{List of Tables}

Table 1: The characterizations of the MN array used in this study

\begin{tabular}{lll}
\hline Name & Parameters & Value $(\boldsymbol{\mu m})$ \\
\hline Adminpatch MN 1500 & Length & 1500 \\
& Width & 480 \\
& Thickness & 78 \\
Adminpatch MN 1200 & Space between MNs & 1546 \\
& Length & 1200 \\
& Width & 480 \\
In-house fabricated MN & Thickness & 78 \\
& Space between MNs & 1252 \\
& Length & 750 \\
& Diameter & 250 \\
& Space between MNs & 500 \\
\hline
\end{tabular}


Figure 1: (a). A schematic diagram of the experimental rig which is an improved version of the one used by Zhang et al. ${ }^{41}$; (b). A schematic diagram of the agarose gel mold

Figure 2: (a) A SEM image of the irregular stainless steel (biocompatible) micro-particles (b) A SEM image of the spherical stainless steel micro-particles

Figure 3: The image of MN arrays: (a) AdminPatch MN 1200 (b) In-house fabricated MN array

Figure 4: Skin mimicking based on the dynamic viscoelastic properties by using agarose gel: (a) storage modulus against angular frequency, (b) loss modulus against angular frequency, (c) dynamic viscosity against angular frequency

Figure 5: The MN insertion in the various concentration of agarose

Figure 6: The effect of the mesh pore size on micro-particle penetration (a) particles passed through a mesh of $178 \mu \mathrm{m}$ pore size (b) particles passed through a mesh of $310 \mu \mathrm{m}$ pore size (operating pressure: 5 bar; agarose gel concentration: $0.0265 \mathrm{~g} / \mathrm{ml}$ )

Figure 7: The effect of the particle size and operating pressure on the penetration depth. Please note that the $18 \mu \mathrm{m}$ and $30 \mu \mathrm{m}$ particles are the regular (spherical) and irregular stainless steel micro-particle, respectively (agarose gel concentration: $0.0265 \mathrm{~g} / \mathrm{ml}$ )

Figure 8: The micro-particle penetration in the skin mimicked concentration of agarose based on the application of AdminPatch MN 1500 (a) Spherical micro-particle of $18 \mu \mathrm{m}$ average diameter, and (b) irregular micro-particles of $30 \mu \mathrm{m}$ average diameter (operating pressure: 4.5 bar, mesh pore size: $178 \mu \mathrm{m}$, agarose gel concentration: $0.0265 \mathrm{~g} / \mathrm{ml}$ )

Figure 9: The effect of the MN length on the penetration depth (particle type: spherical stainless steel micro-particle, agarose gel concentration: $0.0265 \mathrm{~g} / \mathrm{ml}$ )

Figure 10: The effect of the agarose gel concentration on the penetration depth (operating pressure: 4.5 bar; mesh pore size: $178 \mu \mathrm{m}$; particle type: spherical stainless steel micro-particle)

Figure 11: A schematic cross-section of the skin: (a) the normally diffusion route (b) the route of solid MN assisted micro-particle delivery (c) route of needle free micro-particle delivery ${ }^{10,40,41}$ 
Figure 1: (a). A schematic diagram of the experimental rig which is an improved version of the one used by Zhang et al. ${ }^{41}$; (b). A schematic diagram of the agarose gel mold

(a)
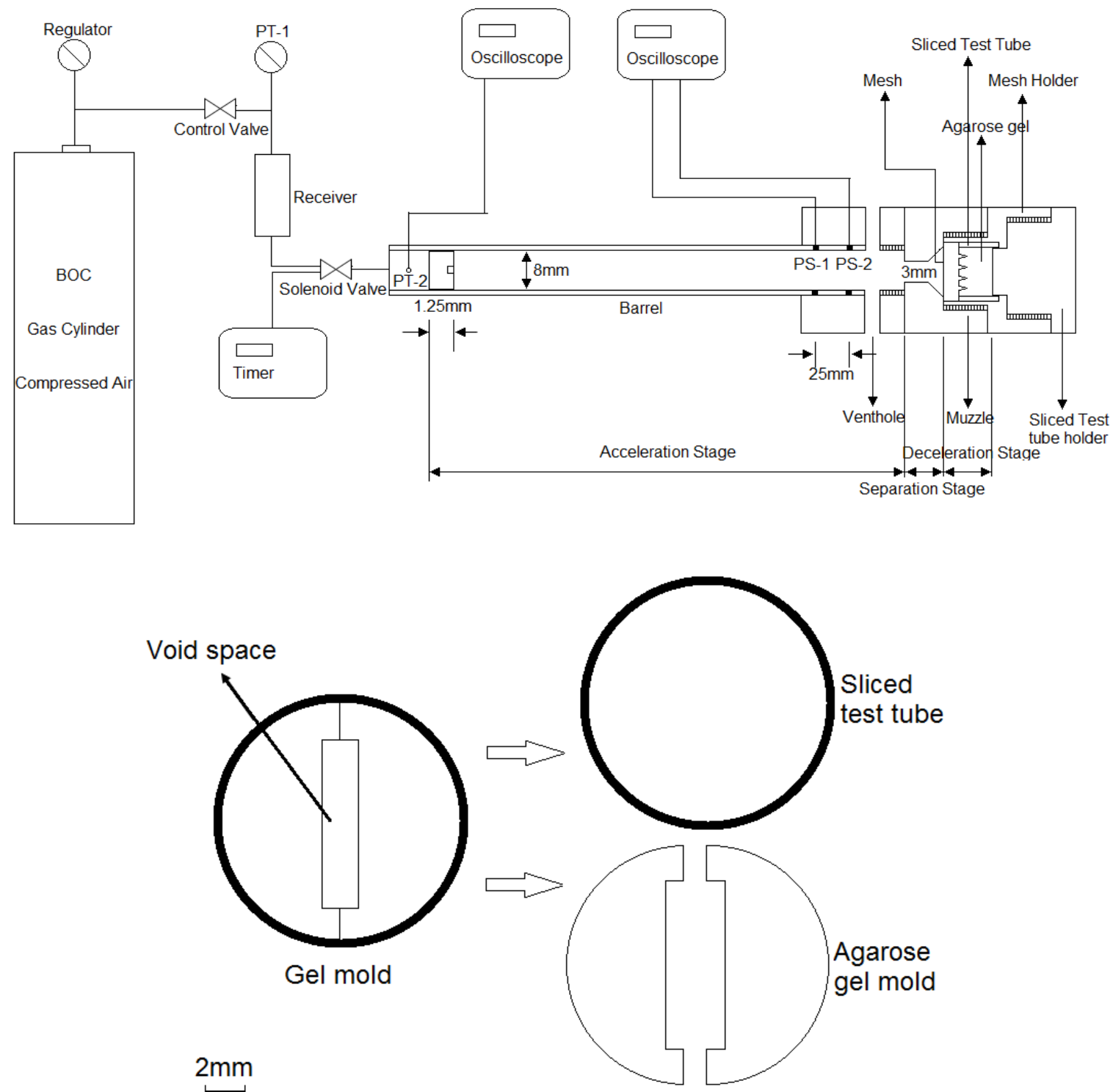

(b) 
Figure 2: (a) A SEM image of the irregular stainless steel (biocompatible) micro-particles (b) A SEM image of the spherical stainless steel micro-particles
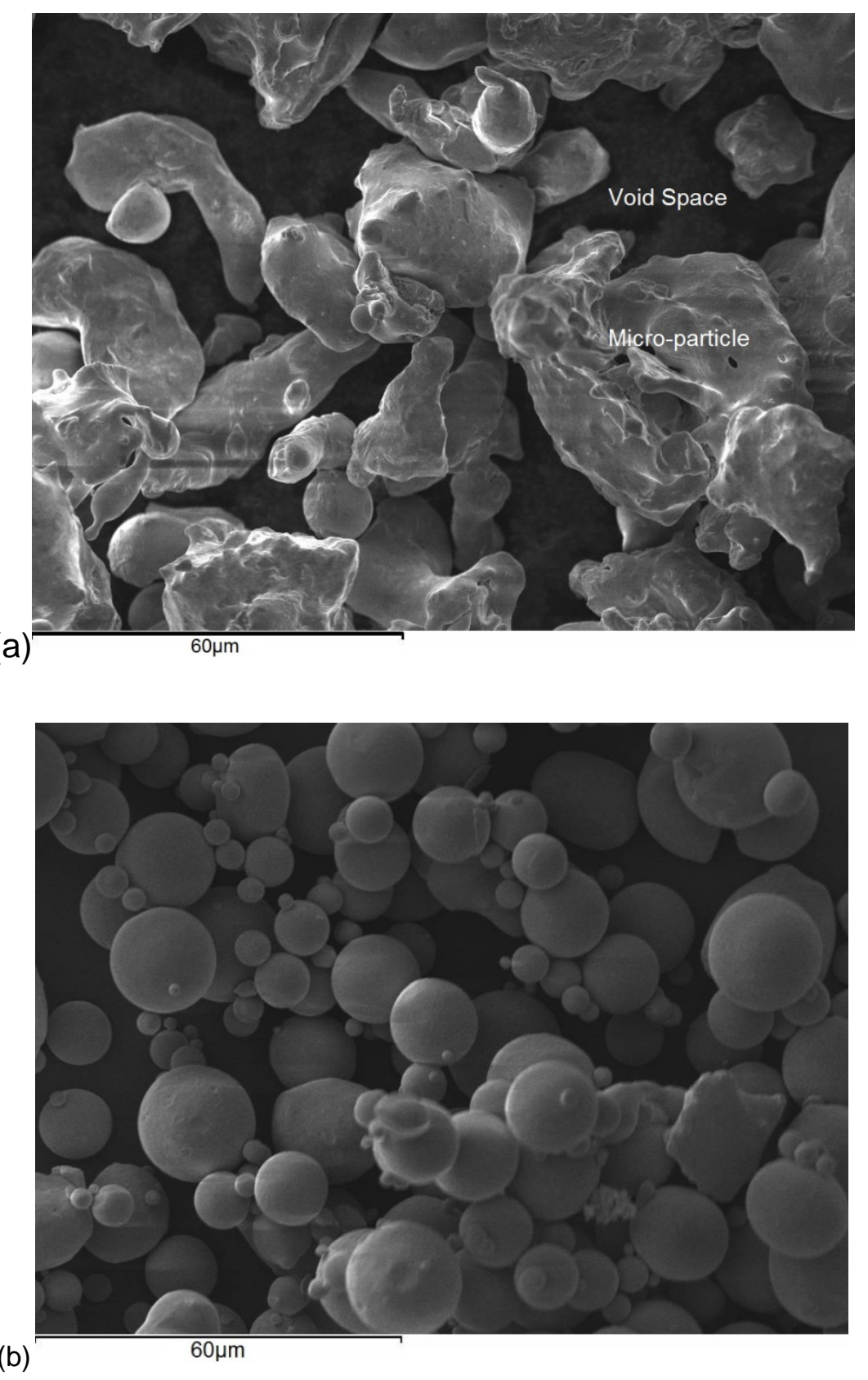
Figure 3: The image of MN arrays: (a) AdminPatch MN 1200 (b) In-house fabricated MN array

(a)
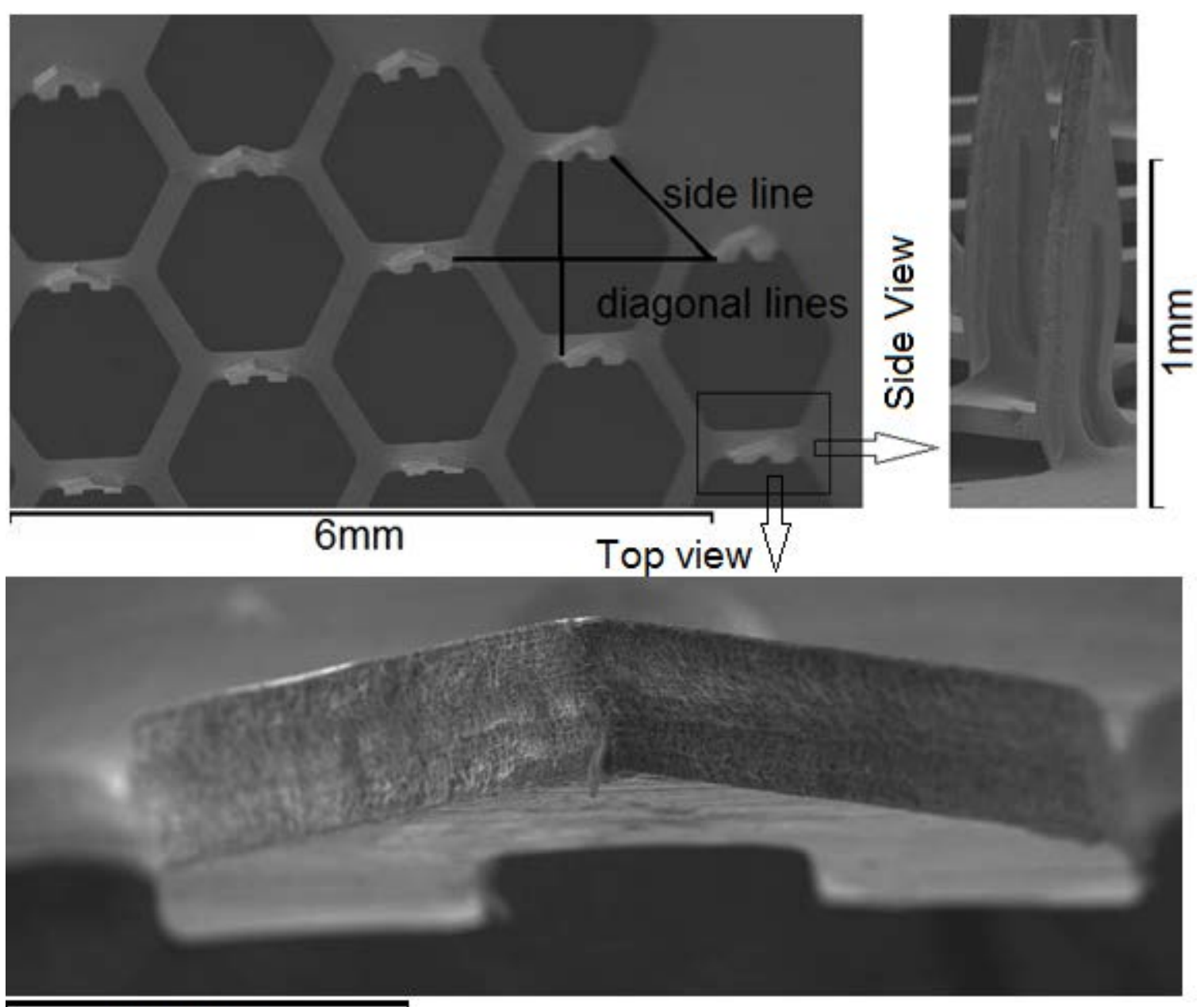

$200 \mu \mathrm{m}$

(b)

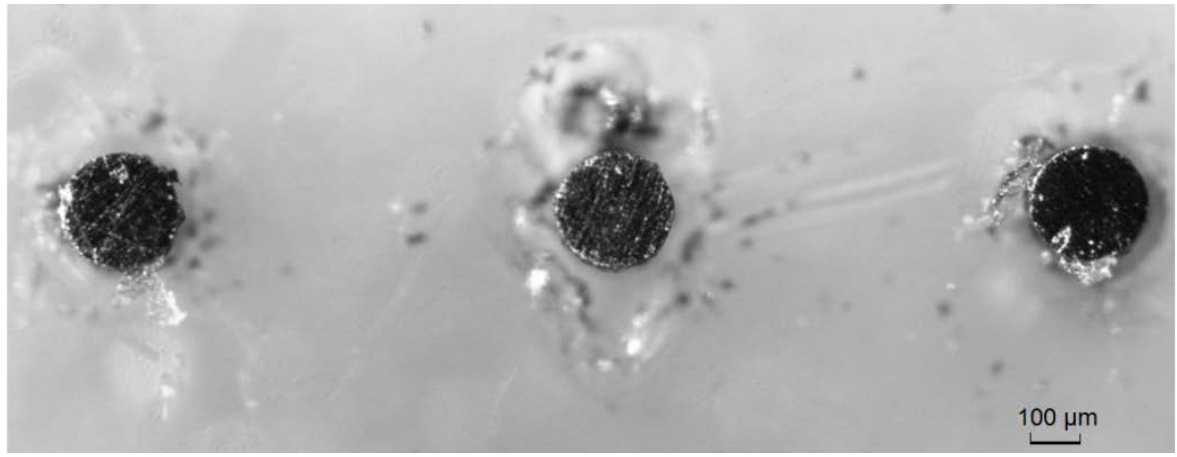


Figure 4: Skin mimicking based on the dynamic viscoelastic properties by using agarose gel: (a) storage modulus against angular frequency, (b) loss modulus against angular frequency, (c) dynamic viscosity against angular frequency

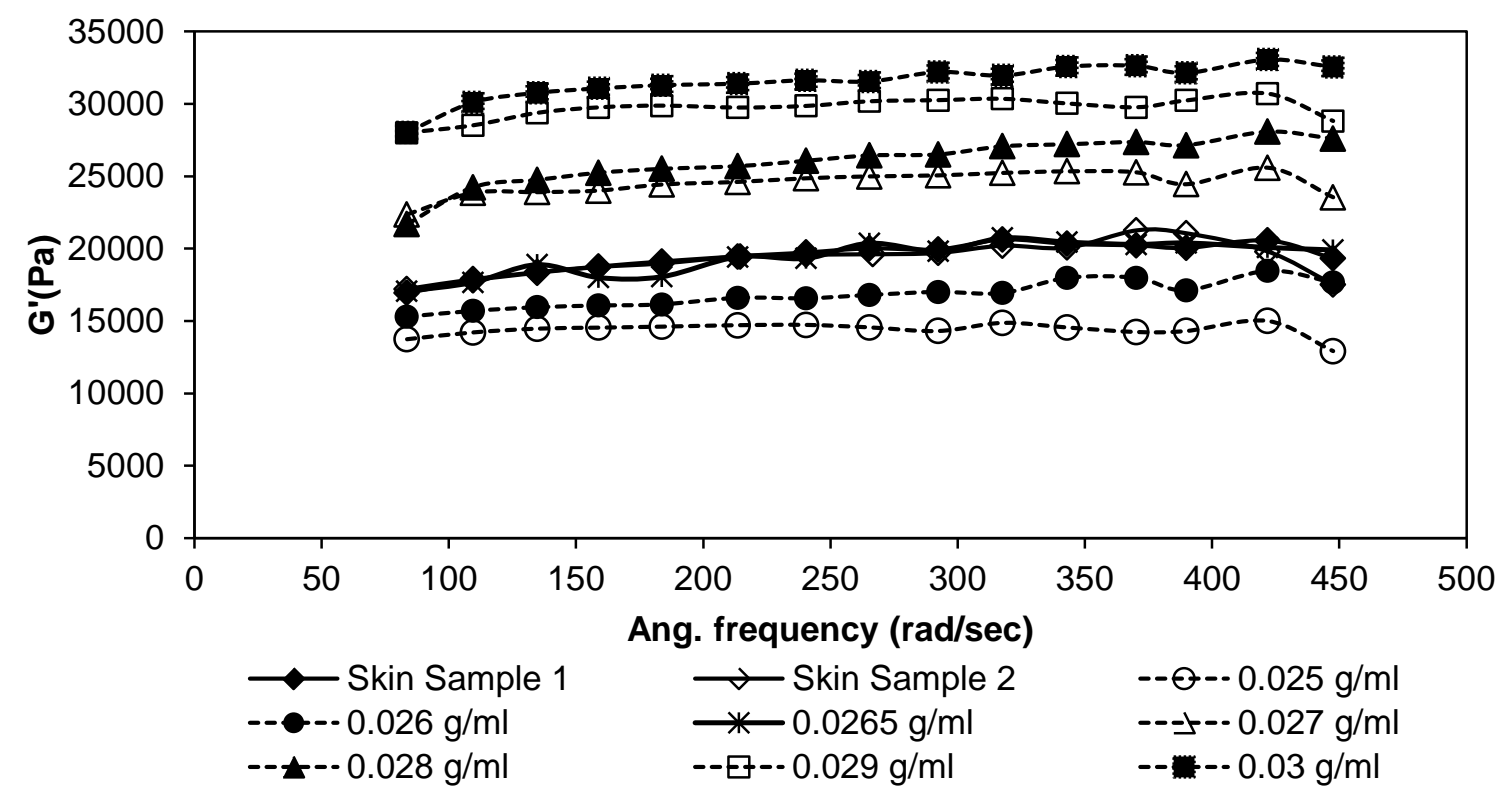

(a)

(b)

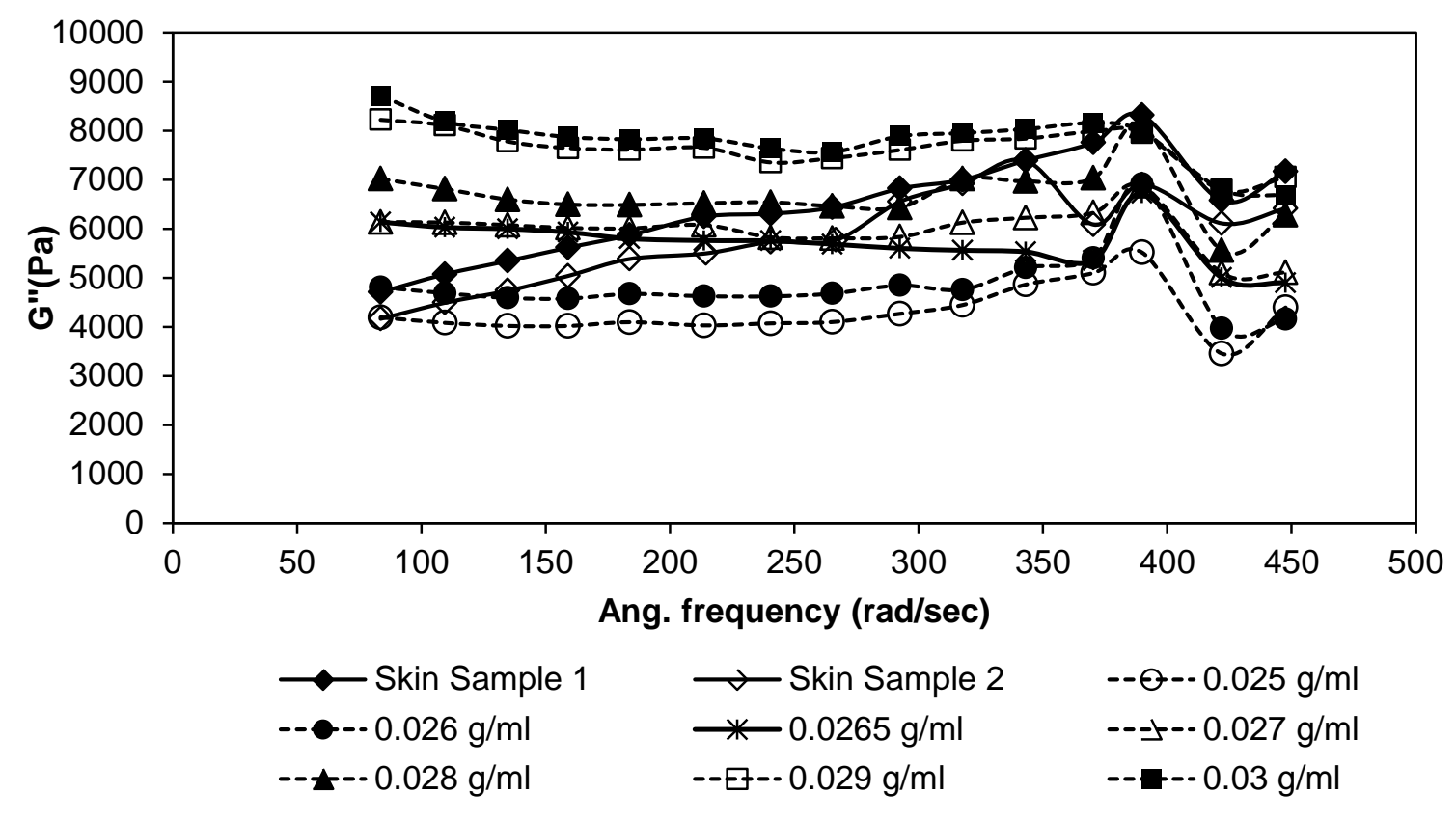

(c) 


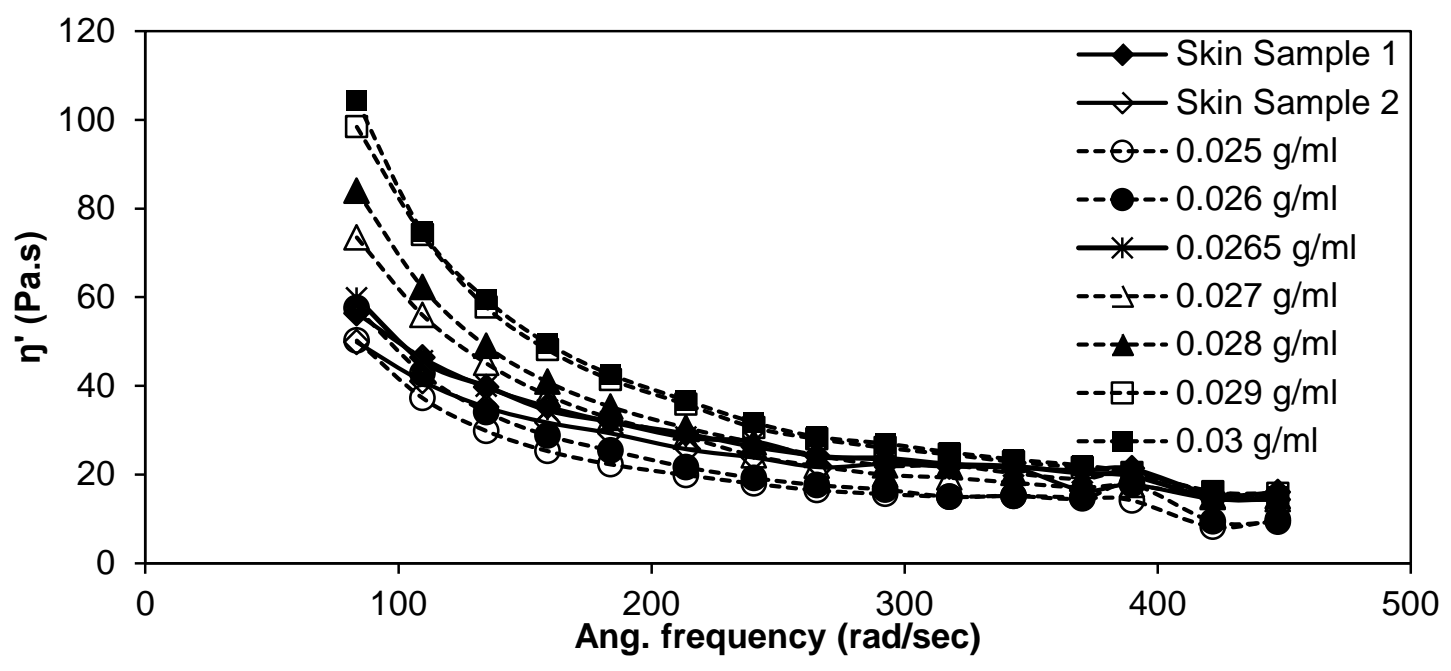


Figure 5: The MN insertion in the various concentration of agarose

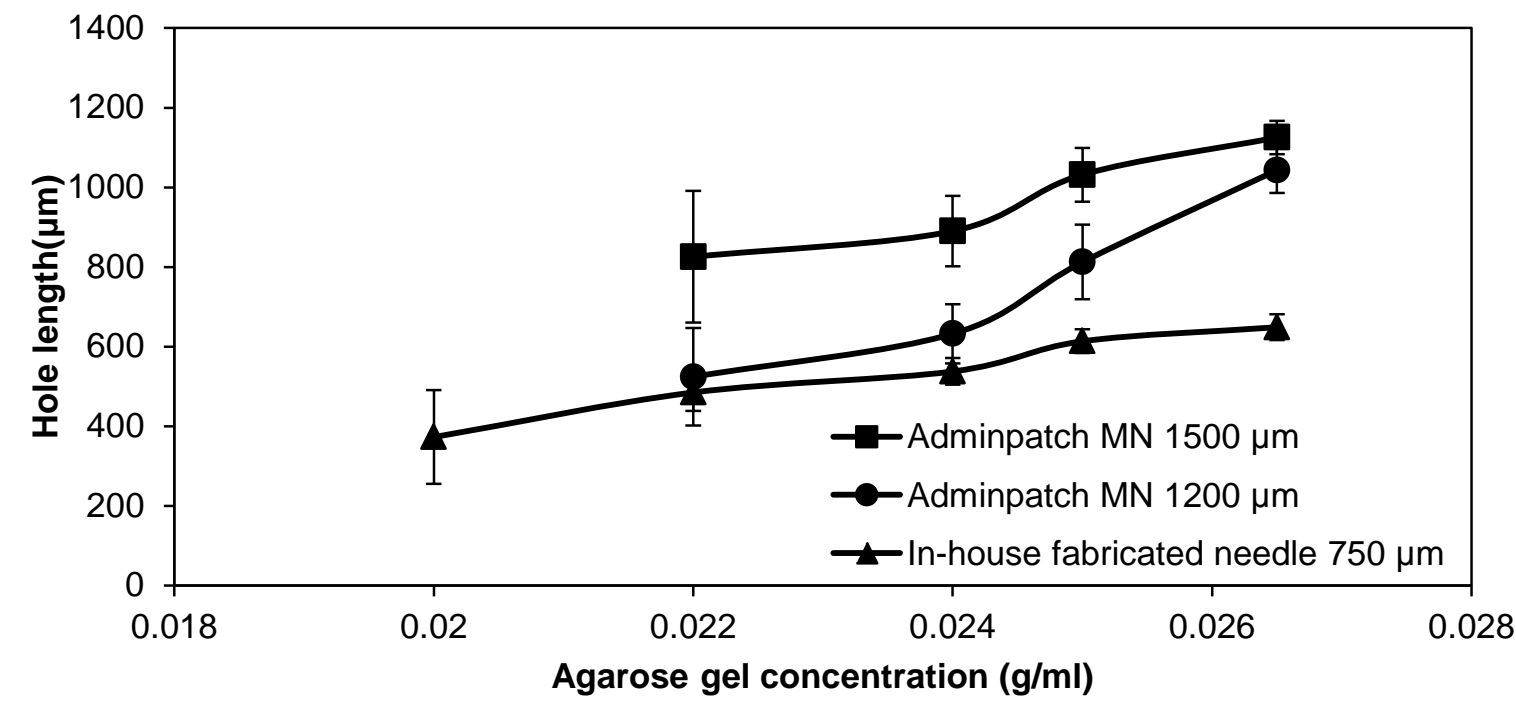


Figure 6: The effect of the mesh pore size on micro-particle penetration (a) particles passed through a mesh of $178 \mu \mathrm{m}$ pore size (b) particles passed through a mesh of $310 \mu \mathrm{m}$ pore size (operating pressure: 5 bar; agarose gel concentration: $0.0265 \mathrm{~g} / \mathrm{ml}$ )

(a)
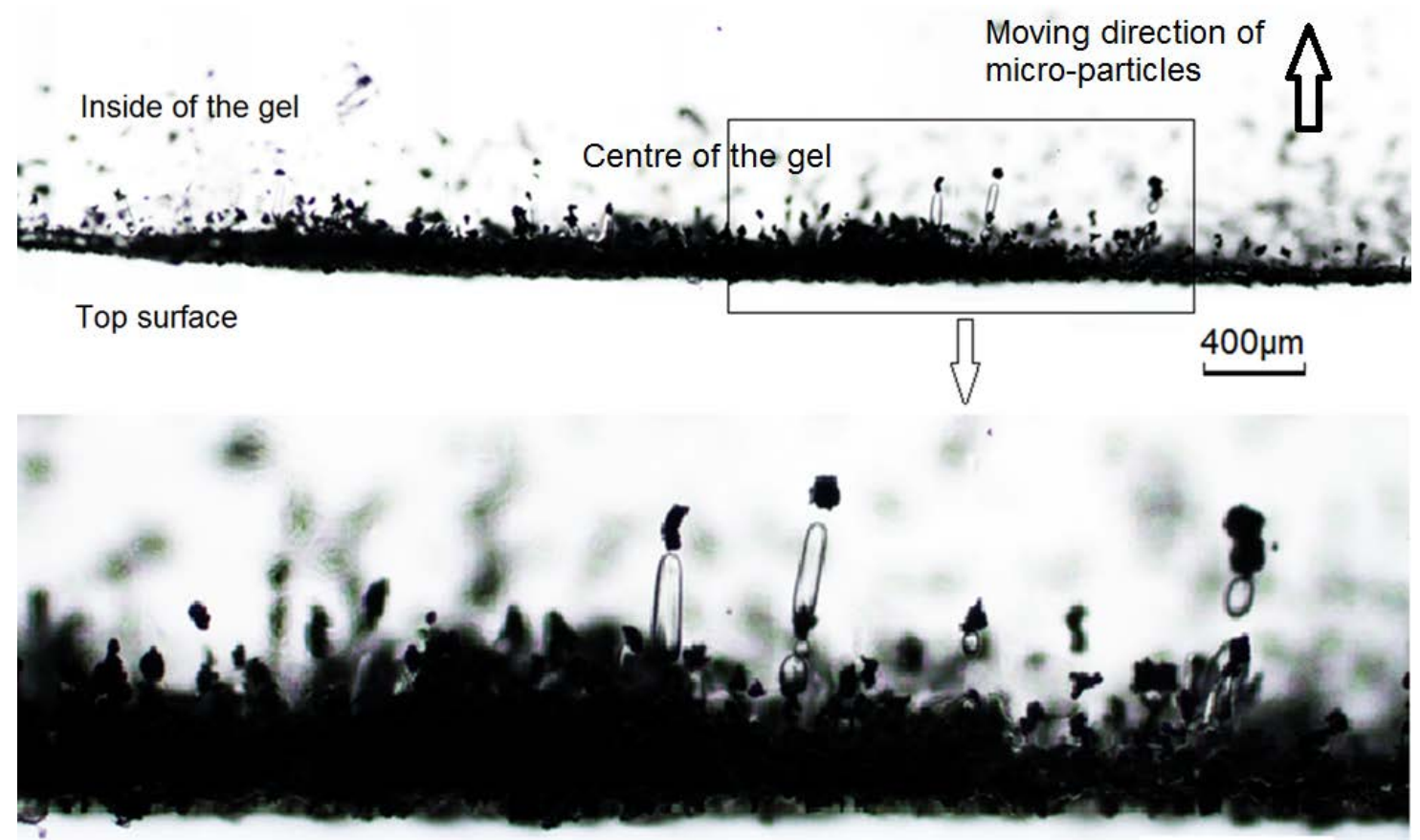

$100 \mu \mathrm{m}$

(b)

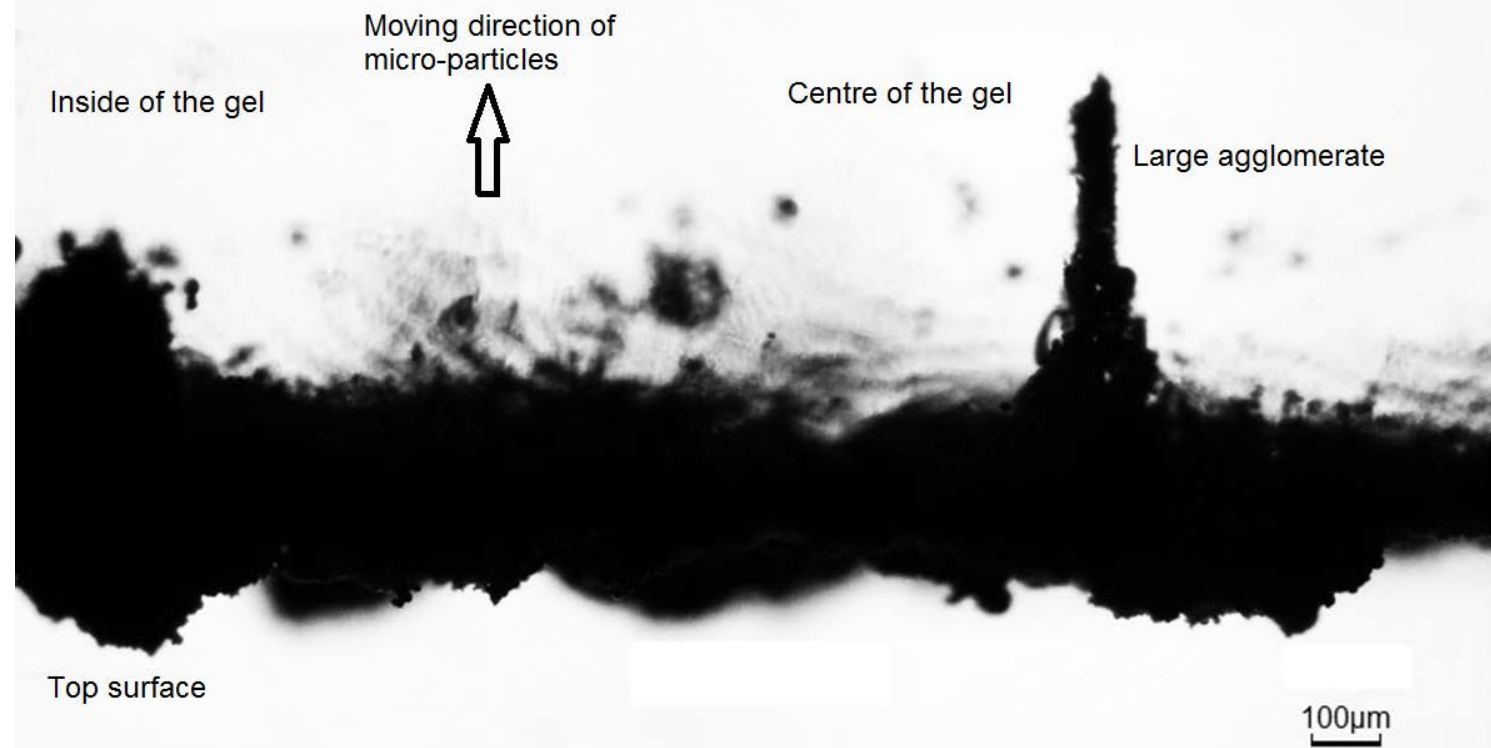


Figure 7: The effect of the particle size and operating pressure on the penetration depth. Please note that the $18 \mu \mathrm{m}$ and $30 \mu \mathrm{m}$ particles are the regular (spherical) and irregular stainless steel micro-particle, respectively (agarose gel concentration: $0.0265 \mathrm{~g} / \mathrm{ml}$ )

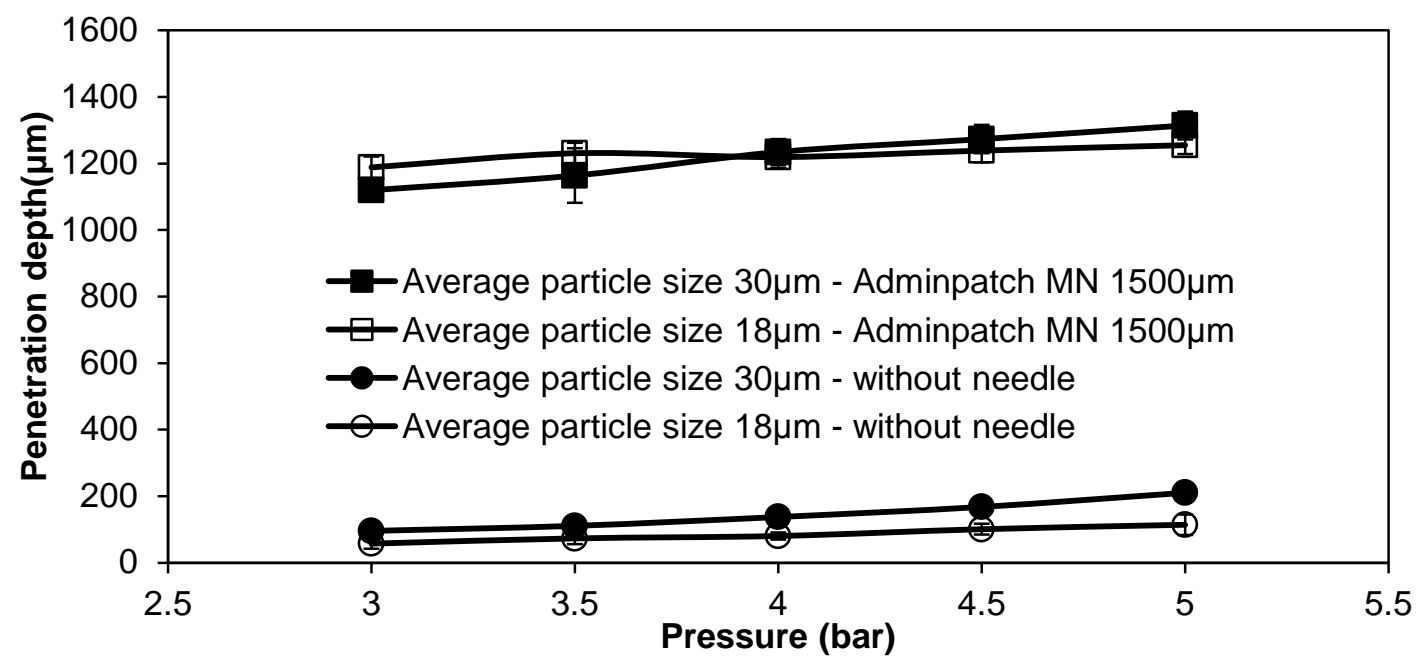


Figure 8: The micro-particle penetration in the skin mimicked concentration of agarose based on the application of AdminPatch MN 1500 (a) Spherical micro-particle of $18 \mu \mathrm{m}$ average diameter, and (b) irregular micro-particles of $30 \mu \mathrm{m}$ average diameter (operating pressure: 4.5 bar, mesh pore size: $178 \mu \mathrm{m}$, agarose gel concentration: $0.0265 \mathrm{~g} / \mathrm{ml}$ )

(a)
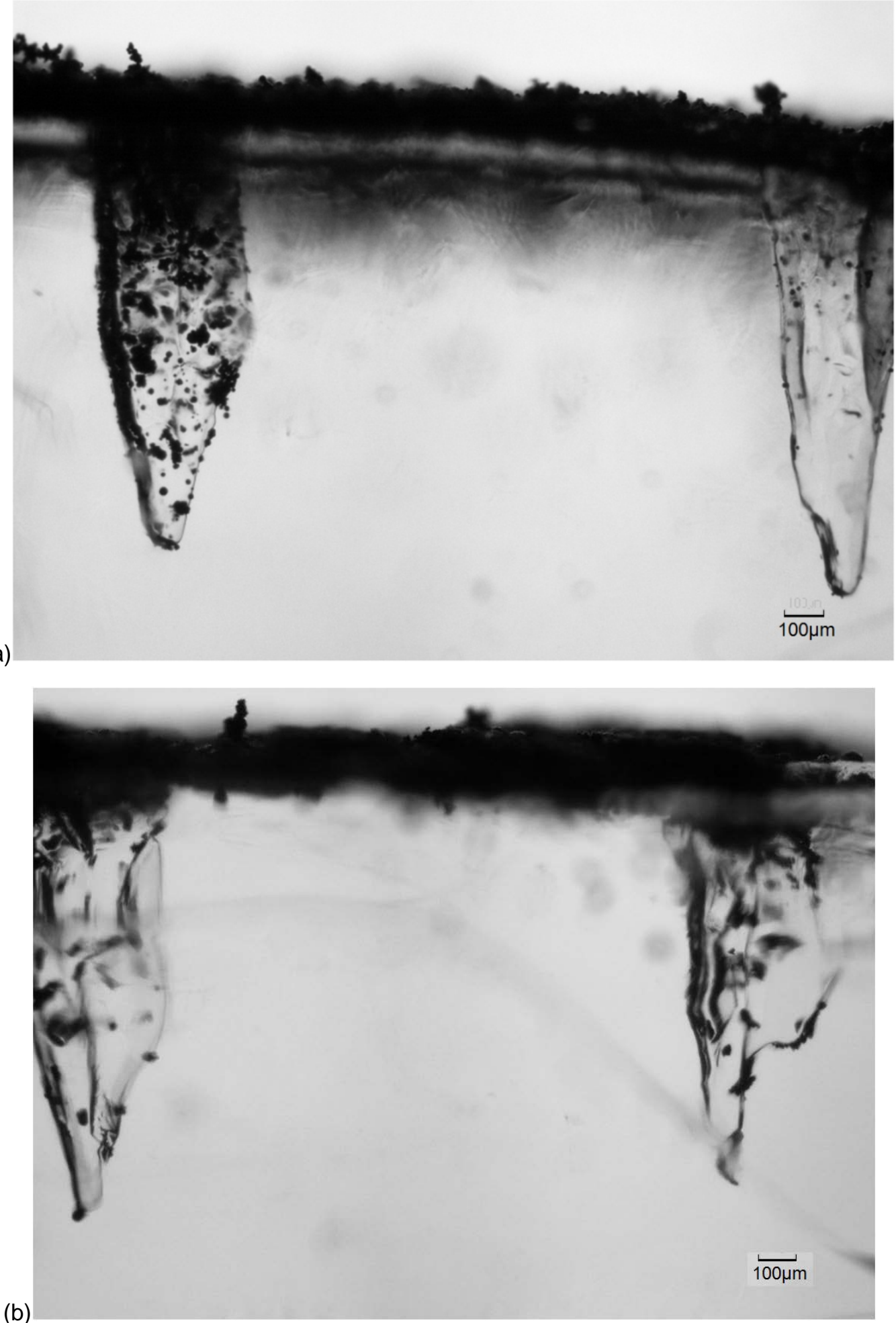
Figure 9: The effect of the MN length on the penetration depth (particle type: spherical stainless steel micro-particle, agarose gel concentration: $0.0265 \mathrm{~g} / \mathrm{ml}$ )

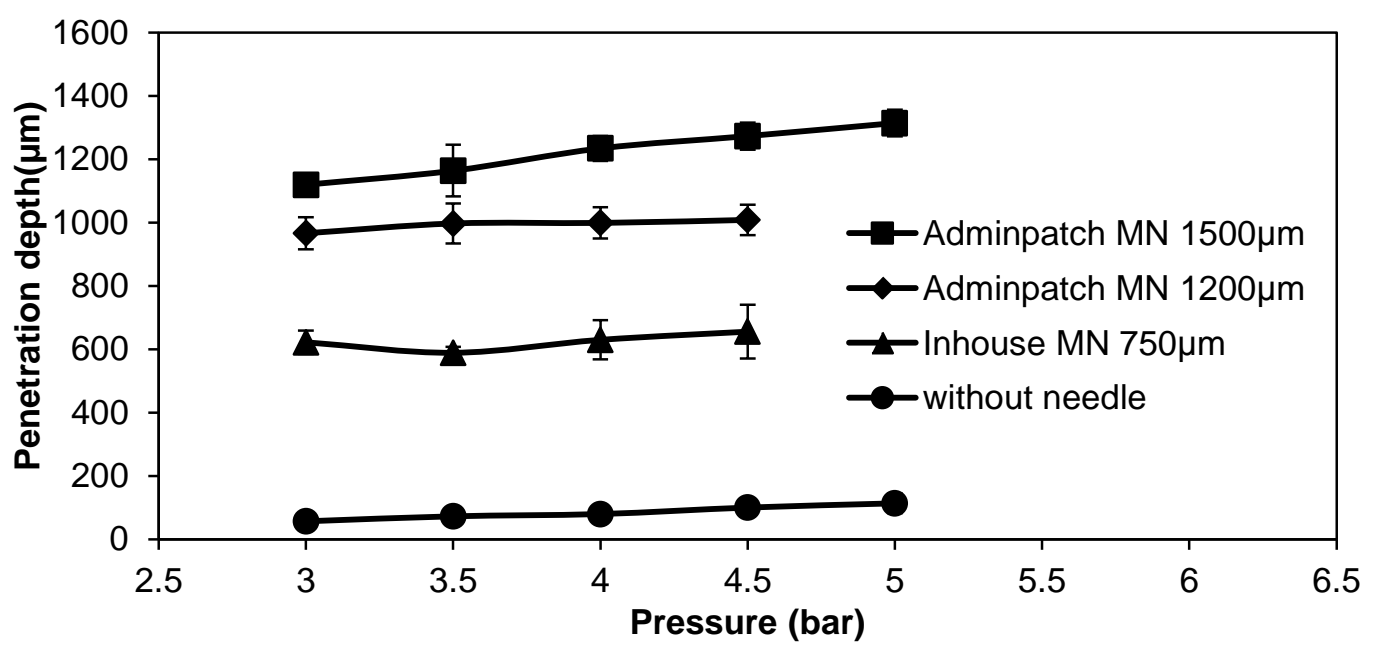


Figure 10: The effect of the agarose gel concentration on the penetration depth (operating pressure: 4.5 bar; mesh pore size: $178 \mu \mathrm{m}$; particle type: spherical stainless steel micro-particle)

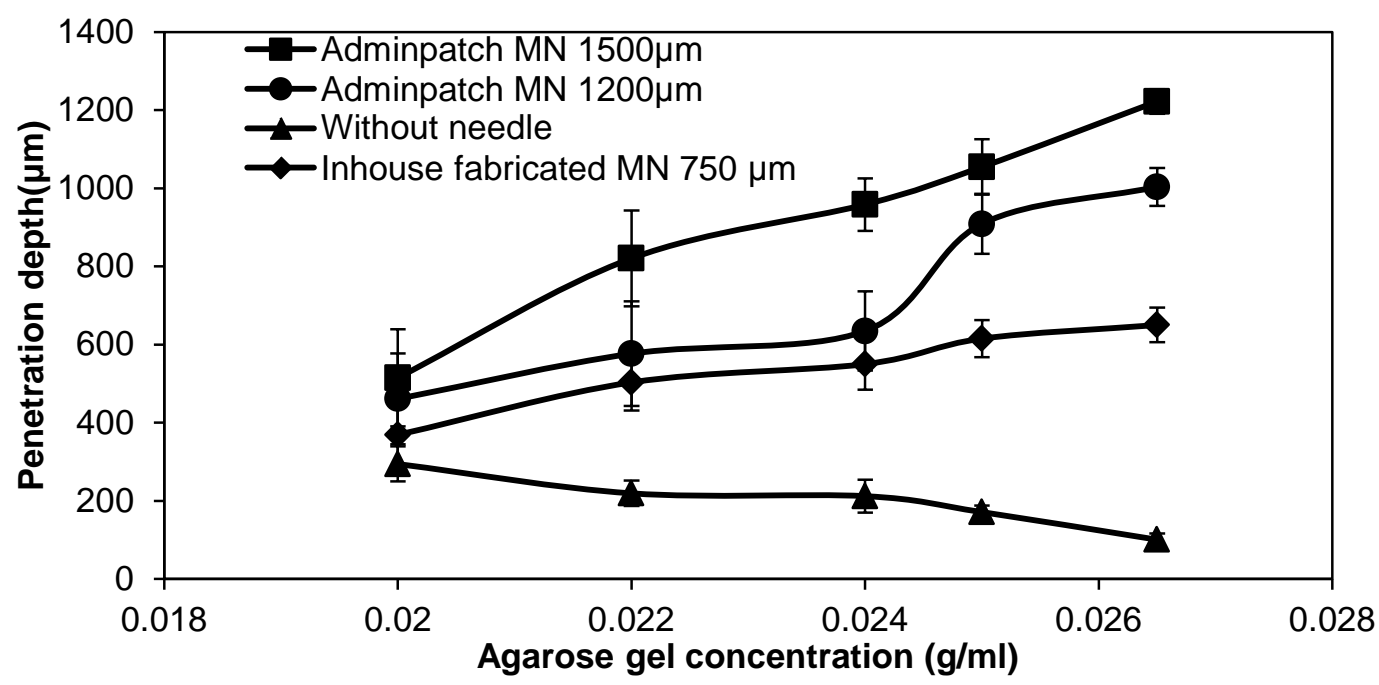


Figure 11: A schematic cross-section of the skin: (a) the normally diffusion route (b) the route of solid MN assisted micro-particle delivery (c) route of needle free micro-particle delivery ${ }^{10,40,41}$

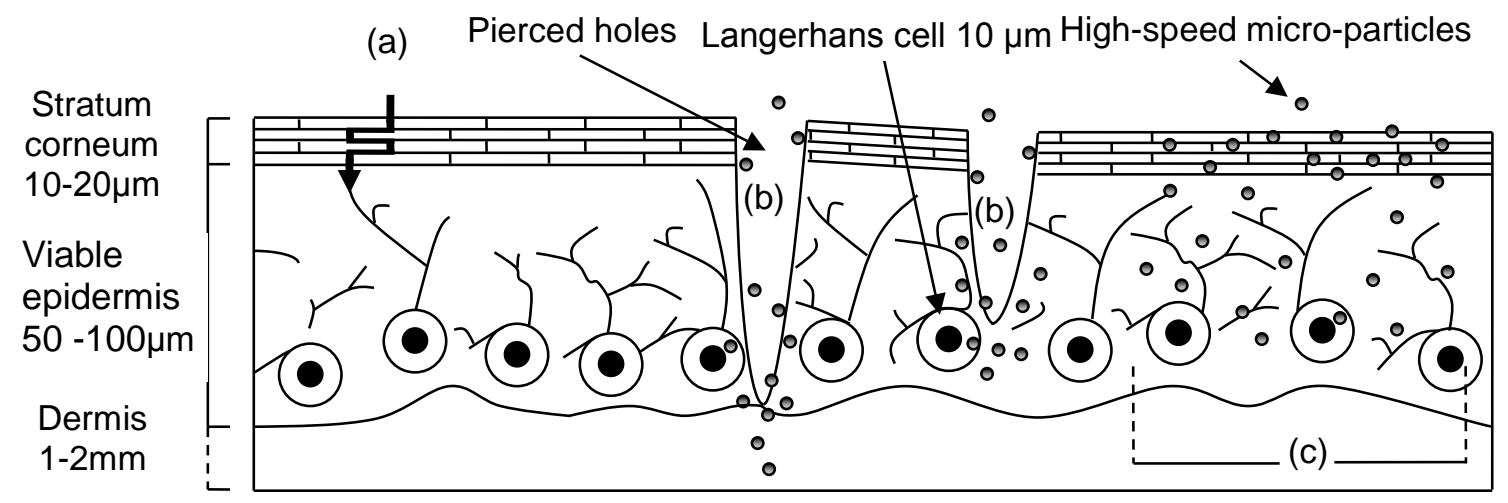

